\title{
MOMENT-BASED ESTIMATION OF SMOOTH TRANSITION REGRESSION MODELS WITH ENDOGENOUS VARIABLES
}

\author{
Waldyr Dutra Areosa \\ Department of Economics, Pontifical Catholic University of Rio de Janeiro \\ Banco Central do Brasil \\ E-mail: wdutra@econ.puc-rio.br
}

\section{Michael McAleer}

School of Economics and Commerce, University of Western Australia

Econometric Institute, Erasmus University Rotterdam

E-mail: michael.mcaleer@gmail.com

Marcelo C. Medeiros

Department of Economics, Pontifical Catholic University of Rio de Janeiro

E-mail: mcmeecon.puc-rio.br

Econometric Institute Report Number EI 2008-36

\begin{abstract}
Nonlinear regression models have been widely used in practice for a variety of time series and cross-section datasets. For purposes of analyzing univariate and multivariate time series data, in particular, Smooth Transition Regression (STR) models have been shown to be very useful for representing and capturing asymmetric behavior. Most STR models have been applied to univariate processes, and have made a variety of assumptions, including stationary or cointegrated processes, uncorrelated, homoskedastic or conditionally heteroskedastic errors, and weakly exogenous regressors. Under the assumption of exogeneity, the standard method of estimation is nonlinear least squares. The primary purpose of this paper is to relax the assumption of weakly exogenous regressors and to discuss moment based methods for estimating STR models. The paper analyzes the properties of the STR model with endogenous variables by providing a diagnostic test of linearity of the underlying process under endogeneity, developing an estimation procedure and a misspecification test for the STR model, presenting the results of Monte Carlo simulations to show the usefulness of the model and estimation method, and providing an empirical application for inflation rate targeting in Brazil. We show that STR models with endogenous variables can be specified and estimated by a straightforward application of existing results in the literature.

KEYWORDS: Smooth transition, nonlinear models, nonlinear instrumental variables, generalized method of moments, endogeneity, inflation targeting.
\end{abstract}




\section{INTRODUCTION AND MOTIVATION}

Nonlinear regression models have been widely used in practice for a variety of time series and crosssection datasets (see Granger and Teräsvirta (1993) for some examples in economics). For purposes of analyzing univariate and multivariate time series data, in particular, Smooth Transition Regression (STR) models, initially proposed in its univariate form by Chan and Tong (1986), and further developed in Luukkonen, Saikkonen, and Teräsvirta (1988) and Teräsvirta (1994,1998), have been shown to be very useful for representing and capturing asymmetric behavion. van Dijk, Teräsvirta, and Franses (2002) provide a useful review of time series STR models.

Most STR models have been applied to univariate processes under a variety of assumptions. For example, although stationarity is imposed in the vast majority of time series applications, Choi and Saikkonnen (2004a,b) considered the case of STR models with cointegrated variables. Conditional heteroskedasticity has been analyzed in several papers, for example, in Lundbergh and Teräsvirta (1998) and Li, Ling, and McAleer (2002)2. However, under stationarity or cross-section applications, the covariates have been assumed to be weakly exogeneous with respect to the parameters of interest. Under the assumption of exogeneity, the standard method of estimation is nonlinear least squares, and the asymptotic properties of the estimators have been discussed in Mira and Escribano (2000), Suarez-Fariñas, Pedreira, and Medeiros (2004), and Medeiros and Veiga (2005), among others. Nonlinear least squares is equivalent to quasi-maximum likelihood or, when the errors are Gaussian, to conditional maximum likelihood.

The primary purpose of this paper is to relax the assumption of weakly exogenous regressors and to provide a generalized method of moments (GMM) estimator for recovering the parameters of STR models. The estimator considered here is equivalent to the nonlinear instrumental variables (IV) estimator proposed by Amemiya (1974). The paper analyzes the properties of the STR model with endogenous variables by providing a diagnostic test of linearity of the underlying process under endogeneity, developing an estimation procedure and a misspecification test for the STR model, presenting the results of Monte Carlo simulations to show the usefulness of the model and estimation method, and providing an empirical application for inflation rate targeting in Brazil.

Although the treatment of nonlinear IV methods dates back to Amemiya (1974), the estimation of STR models with endogenous regressors does not yet seem to have been analyzed. The only exception is Caner and Hansen (2004), where the authors consider a threshold model with endogenous regression. However, in their case, they assume that the transition (threshold) variable is weakly exogenous. Furthermore, most previous work has focused on independent and identically distributed (IID) data and not on time series models. We show that STR models with endogenous variables can be specified and estimated by straightforward application of existing results in the literature under mild regularity conditions.

\footnotetext{
${ }^{1}$ The term "smooth transition" in its present meaning first appeared in Bacon and Watts (1971). They presented their smooth transition model as a generalization of models of two intersecting lines with an abrupt change from one linear regression to another at some unknown change point. Goldfeld and Quandt (1972, pp. 263-264) generalized the so-called two-regime switching regression model using the same idea.

${ }^{2}$ See McAleer (2005) for a discussion of univariate and multivariate conditional volatility models.
} 
The rest of of the paper is organized as follows. Section 2 briefly reviews the literature on moment based estimation for nonlinear regression models. The model and the main assumptions are described in Section 3, while the linearity test is discussed in Section 4. The estimation procedure and the asymptotic properties of the estimators are analyzed in Section 5 Section 6 describes some misspecification tests. Section 7 presents Monte Carlo simulations in order to evaluate the finite sample properties of the tests and the estimation procedure. An empirical application for inflation rate targeting in Brazil is presented in Section 8 . Finally, Section 9 concludes the paper. All technical proofs are given in the Appendix.

\section{Generalized Method of Moments and Instrumental Variable Estimation for NONLINEAR REGRESSION}

As in Amemiya (1974), consider the following assumption:

ASSUMPTION 1. The sequence $\left\{y_{t}\right\}_{t=1}^{T}, T>0$, is generated from the following nonlinear model:

$$
y_{t}=g\left(\mathbf{x}_{t} ; \boldsymbol{\psi}_{0}\right)+u_{t}
$$

where $g\left(\mathbf{x}_{t} ; \boldsymbol{\psi}_{0}\right)$ is a nonlinear function of covariates $\mathbf{x}_{t} \in \mathbb{R}^{q_{x}}$ and is indexed by the "true" parameter vector $\boldsymbol{\psi}_{0} \in \boldsymbol{\Psi} \subseteq \mathbb{R}^{K}$, and $\left\{u_{t}\right\}_{t=1}^{T}$ is a sequence of zero mean random variables, $\mathbb{E}\left(u_{t}\right)=0, \forall t$. Furthermore, $\mathbb{E}\left(u_{t}^{2}\right)=\sigma_{0}^{2}<\infty, \forall t$, and $\mathbb{E}\left(u_{t} u_{s}\right)=0, \forall t \neq s$. Finally, the variables $\mathbf{x}_{t}$ are endogenous in the sense that $\mathbb{E}\left(u_{t} \mid \mathbf{x}_{t}\right) \neq 0$.

Under Assumption $1 \mathbb{E}\left(y_{t} \mid \mathbf{x}_{t}\right) \neq g\left(\mathbf{x}_{t} ; \boldsymbol{\psi}_{0}\right)$ and the nonlinear least squares estimator (NLSE) of the parameters of interest $\boldsymbol{\psi}_{0}$ might be inconsistent as long as $\mathbb{E}\left[u_{t} \dot{\mathbf{g}}\left(\mathbf{x}_{t} ; \boldsymbol{\psi}_{0}\right)\right] \neq 0$, where

$$
\dot{\mathrm{g}}\left(\mathbf{x}_{t} ; \boldsymbol{\psi}_{0}\right)=\left.\frac{\partial g\left(\mathbf{x}_{t} ; \boldsymbol{\psi}\right)}{\partial \boldsymbol{\psi}}\right|_{\boldsymbol{\psi}=\boldsymbol{\psi}_{0}}
$$

Consider a vector of exogenous (instrumental) variables $\mathbf{w}_{t} \in \mathbb{R}^{q_{w}}$ and define a set of valid instruments $\mathbf{z}_{t} \equiv \mathbf{z}\left(\mathbf{w}_{t}\right) \in \mathbb{R}^{q_{z}}, q_{z} \geq K$, where $\mathbf{z}\left(\mathbf{w}_{t}\right): \mathbb{R}^{q_{w}} \rightarrow \mathbb{R}_{q_{z}}$ is a vector-valued function of $\mathbf{w}_{t}$, such that $\mathbb{E}\left(\mathbf{z}_{t} u_{t}\right)=\mathbf{0}$. Therefore, we have $q_{z}$ moment conditions that can be cast into a generalized method of moments $(\mathrm{GMM})$ framework. Defining $\mathbf{Y}_{t}=\left(y_{t}, \mathbf{x}_{t}^{\prime}, \mathbf{z}_{t}^{\prime}\right)^{\prime}$ and $\mathbf{h}\left(\mathbf{Y}_{t} ; \boldsymbol{\psi}\right)=\frac{1}{T} \sum_{t=1}^{T} \mathbf{z}_{t}\left[y_{t}-g\left(\mathbf{x}_{t} ; \boldsymbol{\psi}\right)\right] \equiv$ $\frac{1}{T} \sum_{t=1}^{T} \mathbf{z}_{t} u_{t}(\boldsymbol{\psi})$, the GMM estimator is the solution to the following nonlinear optimization problem:

$$
\widehat{\boldsymbol{\psi}}_{G M M}=\underset{\boldsymbol{\psi} \in \mathbf{\Psi}}{\operatorname{argmin}}\left[\mathbf{h}\left(\mathbf{Y}_{t} ; \boldsymbol{\psi}\right)^{\prime} \widehat{\boldsymbol{\Omega}}^{-1} \mathbf{h}\left(\mathbf{Y}_{t} ; \boldsymbol{\psi}\right)\right]
$$

where $\widehat{\boldsymbol{\Omega}}$ is any consistent estimator of $\boldsymbol{\Omega}=\mathbb{E}\left[u_{t}^{2} \mathbf{z}_{t} \mathbf{z}_{t}^{\prime}\right]=\sigma_{0}^{2} \mathbb{E}\left[\mathbf{z}_{t} \mathbf{z}_{t}^{\prime}\right]$. Hence, treating $\sigma_{0}^{2}$ as a constant and using $\frac{1}{T} \sum_{t=1}^{T} \mathbf{z}_{t} \mathbf{z}_{t}^{\prime}$ as a consistent estimator of $\mathbb{E}\left[\mathbf{z}_{t} \mathbf{z}_{t}^{\prime}\right]$, the GMM approach is equivalent to the 
modified nonlinear IV estimator discussed in Amemiya (1974). Equation (2) can be modified as

$$
\begin{aligned}
\widehat{\boldsymbol{\psi}}_{G M M} & =\underset{\boldsymbol{\psi} \in \boldsymbol{\Psi}}{\operatorname{argmin}}\left\{\frac{1}{T} \sum_{t=1}^{T} \mathbf{z}_{t}\left[y_{t}-g\left(\mathbf{x}_{t} ; \boldsymbol{\psi}\right)\right]\right\}^{\prime}\left[\frac{1}{T} \sum_{t=1}^{T} \mathbf{z}_{t} \mathbf{z}_{t}^{\prime}\right]^{-1}\left\{\frac{1}{T} \sum_{t=1}^{T} \mathbf{z}_{t}\left[y_{t}-g\left(\mathbf{x}_{t} ; \boldsymbol{\psi}\right)\right]\right\} \\
& =\underset{\boldsymbol{\psi} \in \boldsymbol{\Psi}}{\operatorname{argmin}} \frac{1}{T}[\mathbf{y}-\mathbf{g}(\mathbf{X} ; \boldsymbol{\psi})]^{\prime} \mathbf{Z}\left(\mathbf{Z}^{\prime} \mathbf{Z}\right)^{-1} \mathbf{Z}^{\prime}[\mathbf{y}-\mathbf{g}(\mathbf{X} ; \boldsymbol{\psi})] \\
& =\underset{\boldsymbol{\psi} \in \boldsymbol{\Psi}}{\operatorname{argmin}} \frac{1}{T}[\mathbf{y}-\mathbf{g}(\mathbf{X} ; \boldsymbol{\psi})]^{\prime} \mathbf{P}_{Z}[\mathbf{y}-\mathbf{g}(\mathbf{X} ; \boldsymbol{\psi})],
\end{aligned}
$$

where $\mathbf{y}=\left(y_{1}, \ldots, y_{T}\right)^{\prime}, \mathbf{X}=\left(\mathbf{x}_{1}, \ldots, \mathbf{x}_{T}\right)^{\prime}$ is a $\left(T \times q_{x}\right)$ matrix of endogenous variables, $\mathbf{g}(\mathbf{X} ; \boldsymbol{\psi})=$ $\left[g\left(\mathbf{x}_{1} ; \boldsymbol{\psi}\right), \ldots, g\left(\mathbf{x}_{T} ; \boldsymbol{\psi}\right)\right]^{\prime}$, and $\mathbf{Z}=\left(\mathbf{z}_{1}, \ldots, \mathbf{z}_{T}\right)^{\prime}$ is a $\left(T \times q_{z}\right)$ matrix of valid instruments.

When the model is nonlinear only in the variables, Kelejian (1971) showed consistency of the IV estimation when polynomials of the exogenous variables are used as instruments. Bowden and Turkington (1981) compared different IV estimators for the nonlinear-in-variables model. Amemiya (1974) first discussed the estimation of (1) when the function $g\left(\mathbf{x}_{t} ; \boldsymbol{\psi}_{0}\right)$ is nonlinear both in the parameters and in the variables. He proved consistency and asymptotic normality of (3) for IID data and when the instruments are assumed to be fixed in repeated samples, and also demonstrated efficiency of the estimator when the model is nonlinear only in the parameters.

From the first-order conditions for the optimization problem (3), a key (rank) condition for identification is that

$$
\operatorname{plim}_{T \rightarrow \infty} \frac{1}{T} \mathbf{Z}^{\prime} \dot{\mathbf{g}}\left(\mathbf{X} ; \boldsymbol{\psi}_{0}\right)
$$

is of full rank. Thus, the instruments $\mathbf{Z}$ must be correlated with the gradient of the nonlinear function. Even though when $\mathbf{z}_{t}$ is highly correlated with the endogenous variables $\mathbf{x}_{t}$, this might not be case for $\mathbf{z}_{t}$ and $\dot{\mathbf{g}}\left(\mathbf{x}_{t} ; \boldsymbol{\psi}_{0}\right)$. Thus, strong instruments in a linear framework, might be rather weak in a nonlinear setting (see Stock, Wright, and Yogo (2002) for a recent review on weak instruments).

Amemiya (1975) showed that the optimal instruments are given by

$$
\mathbf{z}_{t}\left(\mathbf{w}_{t}\right)=\mathbb{E}\left[\dot{\mathbf{g}}\left(\mathbf{x}_{t} ; \psi_{0}\right) \mid \mathbf{w}_{t}\right]
$$

More recently, Newey (1990) considered asymptotically efficient IV estimation of nonlinear models in an IID framework based on nonparametric estimation of the optimal set of instruments in (4). More specifically, he considered the estimation of the conditional moment in (4) by two different nonparametric techniques, namely nearest-neighbor and series (sieve) approximation. The latter is closely related to the polynomial estimation discussed earlier in Kelejian (1971).

Amemiya (1975) discussed different limited-information estimators of the nonlinear simultaneous equation model and compared their covariance matrices. The author considered the following linear reduced form for $\mathbf{x}_{t}$ :

$$
\mathbf{x}_{t}=\Theta_{0} \mathbf{w}_{t}+\mathbf{v}_{t},
$$

where $\mathbb{E}\left(\mathbf{v}_{t} \mid \mathbf{w}_{t}\right)=\mathbf{0}$, and $\left\{\mathbf{v}_{t}\right\}_{t=1}^{T}$ is a sequence of zero mean IID random variables which are correlated with the structural errors $u_{t}$. Defining $\mathbf{W}=\left(\mathbf{w}_{1}, \ldots, \mathbf{w}_{T}\right)^{\prime}, \widehat{\boldsymbol{\Theta}}=\left(\mathbf{W}^{\prime} \mathbf{W}\right)^{-1} \mathbf{W}^{\prime} \mathbf{X}, \widehat{\mathbf{V}}=\mathbf{X}-\widehat{\boldsymbol{\Theta}} \mathbf{W}$, 
and $\mathbf{u}(\psi)=\mathbf{y}-\mathbf{g}(\mathbf{X} ; \boldsymbol{\psi})$, Amemiya (1975) proposed the modified IV (MIV) estimator given by

$$
\begin{aligned}
\widehat{\boldsymbol{\psi}}_{M I V} & =\underset{\boldsymbol{\psi} \in \boldsymbol{\Psi}}{\operatorname{argmin}} \mathcal{Q}_{M I V, T}(\boldsymbol{\psi}) \\
& =\underset{\boldsymbol{\psi} \in \boldsymbol{\Psi}}{\operatorname{argmin}}[\mathbf{y}-\mathbf{g}(\mathbf{X} ; \boldsymbol{\psi})]^{\prime}\left[\mathbf{I}-\widehat{\mathbf{V}}\left(\widehat{\mathbf{V}}^{\prime} \widehat{\mathbf{V}}\right)^{-1} \widehat{\mathbf{V}}^{\prime}\right][\mathbf{y}-\mathbf{g}(\mathbf{X} ; \boldsymbol{\psi})] \\
& =\underset{\boldsymbol{\psi} \in \boldsymbol{\Psi}}{\operatorname{argmin}}\left\{\mathbf{u}(\boldsymbol{\psi})^{\prime} \mathbf{u}(\boldsymbol{\psi})-\mathbf{u}(\boldsymbol{\psi})^{\prime}\left[\widehat{\mathbf{V}}\left(\widehat{\mathbf{V}}^{\prime} \widehat{\mathbf{V}}\right)^{-1} \widehat{\mathbf{V}}^{\prime}\right] \mathbf{u}(\boldsymbol{\psi})\right\},
\end{aligned}
$$

where $\mathbf{I}$ is a $(T \times T)$ identity matrix.

He showed that (6) is more efficient than (3). The estimator given in (6) is equivalent to the onestep maximum likelihood estimator, given the parameters of the linear reduced form of the exogenous variables.

Finally, Amemiya (1977) considered the maximum likelihood and three-stage least squares estimators of the general nonlinear simultaneous equations model. More recently, Newey and Powell (2003) considered IV estimation of nonparametric models.

\section{The Model and Main Assumptions}

We write a smooth transition regression (STR) model as a special case of (1), and consider the following assumption about the data generating process (DGP):

Assumption 2 (Data Generating Process). The sequence $\left\{y_{t}\right\}_{t=1}^{T}$ is generated by

$$
y_{t}=\boldsymbol{\beta}_{01}^{\prime} \widetilde{\mathbf{x}}_{t}+\boldsymbol{\beta}_{02}^{\prime} \widetilde{\mathbf{x}}_{t} f\left(s_{t} ; \gamma_{0}, c_{0}\right)+u_{t},
$$

where $f\left(s_{t} ; \gamma_{0}, c_{0}\right)$ is the logistic function given by

$$
f\left(s_{t} ; \gamma_{0}, c_{0}\right)=\frac{1}{1+e^{-\gamma_{0}\left(s_{t}-c_{0}\right)}},
$$

$\widetilde{\mathbf{x}}_{t}=\left(1, \mathbf{x}_{L, t}^{\prime}\right), \mathbf{x}_{t}=\left(\mathbf{x}_{L, t}^{\prime}, s_{t}\right)^{\prime} \in \mathbb{R}^{q_{x}}$ is the vector of covariate $\sqrt{3}, \mathbb{E}\left(u_{t} \mid \mathbf{x}_{t}\right) \neq 0$, and $\mathbb{E}\left(u_{t}^{2}\right)=\sigma_{0}^{2}<$ $\infty$.

In this case, $g\left(\mathbf{x}_{t} ; \boldsymbol{\psi}_{0}\right) \equiv \boldsymbol{\beta}_{01}^{\prime} \widetilde{\mathbf{x}}_{t}+\boldsymbol{\beta}_{02}^{\prime} \widetilde{\mathbf{x}}_{t} f\left(s_{t} ; \gamma_{0}, c_{0}\right)$ and $\boldsymbol{\psi}_{0}=\left(\boldsymbol{\beta}_{01}^{\prime}, \boldsymbol{\beta}_{02}^{\prime}, \gamma_{0}, c_{0}\right)^{\prime} \in \mathbb{R}^{K}$. The structural parameters to be estimated are $\psi_{0}$ and $\sigma_{0}^{2}$.

The STR model can be considered as a regime-switching model that allows for two limiting regimes associated with the extreme values of the transition function, $f\left(s_{t} ; \gamma, c\right)=0$ and $f\left(s_{t} ; \gamma, c\right)=1$, where the transition from one regime to the other is smooth. The parameter $c$ can be interpreted as the threshold between the two regimes, in the sense that the logistic function changes monotonically from 0 to 1 as $s_{t}$ increases and $f(c ; \gamma, c)=0.5$. The parameter $\gamma$ determines the smoothness of the transition from one regime to the other. As $\gamma$ becomes very large, the logistic function $f\left(s_{t} ; \gamma, c\right)$ approaches the indicator function and, consequently, the change of $f\left(s_{t} ; \gamma, c\right)$ from 0 to 1 becomes instantaneous at $s_{t}=c$.

We make the following assumptions about the parameters of the model.

\footnotetext{
${ }^{3}$ If $s_{t}$ is an element of $\mathbf{x}_{L, t}$, then $\mathbf{x}_{t}=\mathbf{x}_{L, t}$.
} 
ASSUMPTION 3 (Identification). The parameter vector $\psi_{0}$ is interior to a compact parameter space, $\Psi$. Furthermore, $\gamma_{0}>0$ and $c_{0}$ is interior to the support of the probability distribution of $s_{t}$. If the distribution of $s_{t}$ has infinite support, then $-\infty<\underline{c}<c_{0}<\bar{c}<\infty$.

Assumption 3 is a standard assumption for identification of STR models. The restriction on $\gamma_{0}$ avoids the lack of identification due to the symmetric behavior of the logistic function.

The vector of endogenous variables follows a linear reduced form, as in the following assumption.

ASSUMPTION 4 (Reduced Form). $\mathbf{w}_{t} \in \mathbb{R}^{q_{w}}$ is a vector of exogenous variables such that:

(1) $\mathbf{x}_{t}=\Theta_{0} \mathbf{w}_{t}+\mathbf{v}_{t}$;

(2) $\mathbb{E}\left(u_{t} \mid \mathbf{w}_{t}\right)=0, \forall t$;

(3) $\mathbb{E}\left(\mathbf{v}_{t} \mid \mathbf{w}_{t}\right)=\mathbf{0}, \forall t$;

(4) $\mathbb{E}\left(\mathbf{v}_{t} \mid \mathcal{F}_{t-1}\right)=0$, where $\mathcal{F}_{t-1}$ is defined as in Assumption 6; and

(5) Set $\mathbf{e}_{t}=\left(u_{t}, \mathbf{v}_{t}^{\prime}\right)^{\prime} . \mathbb{E}\left(\mathbf{e}_{t} \mathbf{e}_{\tau}^{\prime}\right)=\delta_{\tau t} \boldsymbol{\Sigma}$, where

$$
\delta_{\tau, t}=\left\{\begin{array}{ll}
1 & \text { if } \tau=t, \\
0 & \text { if } \tau \neq t,
\end{array} \text { and } \boldsymbol{\Sigma}=\left(\begin{array}{cc}
\sigma_{0}^{2} & \boldsymbol{\Sigma}_{u v}^{\prime} \\
\boldsymbol{\Sigma}_{u v} & \boldsymbol{\Sigma}_{v}
\end{array}\right)\right. \text {. }
$$

We consider that there is a set of valid instruments that satisfy the assumption bellow.

AsSUMPtion 5 (Instruments). $\mathbf{Z} \equiv\left[\mathbf{z}\left(\mathbf{w}_{1}\right), \ldots, \mathbf{z}\left(\mathbf{w}_{T}\right)\right]^{\prime}$ is a $\left(T \times q_{z}\right), q_{z} \geq K$, matrix of instruments, such that:

(1) $\mathbf{z}_{t} \equiv \mathbf{z}\left(\mathbf{w}_{t}\right): \mathbb{R}^{q_{w}} \longrightarrow \mathbb{R}^{q_{z}}$ is a linear or nonlinear function of $\mathbf{w}_{t}$, such that $\mathbb{E}\left(\left|\mathbf{z}_{t}\right|\right)<\infty$;

(2) $\operatorname{plim}_{T \rightarrow \infty} \frac{1}{T} \mathbf{Z}^{\prime} \mathbf{Z}$ exists and is nonsingular;

(3) $\frac{1}{T} \mathbf{Z}^{\prime} \dot{\mathbf{g}}(\mathbf{X} ; \boldsymbol{\psi})$ converges in probability uniformly in $\boldsymbol{\psi} \in N\left(\boldsymbol{\psi}_{0}\right)$, where $N\left(\boldsymbol{\psi}_{0}\right)$ is a neighborhood of $\psi_{0}$; and

(4) $\underset{T \rightarrow \infty}{\operatorname{plim}} \frac{1}{T} \mathbf{Z}^{\prime} \mathbf{g}\left(\mathbf{X} ; \boldsymbol{\psi}_{0}\right)$ exists and is of full rank.

Furthermore, the error term is such that:

AsSUMPTION 6 (Error Term). $\left\{u_{t}\right\}_{t=1}^{T}$ is a martingale difference sequence, such that $\mathbb{E}\left(u_{t} \mid \mathcal{F}_{t-1}\right)=0$, where $\mathcal{F}_{t-1}$ is the $\sigma$-field generated by $\left\{\mathbf{x}_{t-j}^{\prime}, \mathbf{w}_{t-j}^{\prime}, u_{t-j}: j \geq 1\right\}$.

In this paper we consider only models with stationary variables.

ASSUMPTION 7 (Stationarity). The sequence $\left\{\mathbf{Y}_{t}\right\}_{t=1}^{T}$, where $\mathbf{Y}_{t}=\left(y_{t}, \mathbf{x}_{t}^{\prime}, \mathbf{z}_{t}^{\prime}\right)^{\prime}$, is stationary and ergodic. Furthermore, $\mathbb{E}\left(\mathbf{x}_{t} \mathbf{x}_{t}^{\prime}\left|s_{t}\right|^{6+\delta}\right)<\infty$ for some $\delta>0$.

The last moment condition in Assumption 7 is important in order to guarantee the existence of the relevant moments in the linearity test to be presented in the next section. 


\section{Linearity Testing Against Smooth Transition Regression}

Consider an STR model as in (7). A convenient null hypothesis of linearity is $\mathcal{H}_{0}: \gamma=0$, against the alternative $\mathcal{H}_{a}: \gamma>0$. Note that model (7) is not identified under the null hypothesis. In order to remedy this problem, we follow Teräsvirta (1994) and expand the logistic function $f\left(s_{t} ; \gamma, c\right)$ into a third-order Taylor expansion around the null hypothesis $\gamma=0$. After merging terms, the resulting model is 4

$$
y_{t}=\boldsymbol{\alpha}_{1}^{\prime} \widetilde{\mathbf{x}}_{t}+\boldsymbol{\alpha}_{2}^{\prime} \widetilde{\mathbf{x}}_{t} s_{t}+\boldsymbol{\alpha}_{3}^{\prime} \widetilde{\mathbf{x}}_{t} s_{t}^{2}+\boldsymbol{\alpha}_{4}^{\prime} \widetilde{\mathbf{x}}_{t} s_{t}^{3}+u_{t}^{*},
$$

where $u_{t}^{*}=u_{t}+R\left(s_{t} ; \gamma, c\right), R\left(s_{t} ; \gamma, c\right)$ is the remainder, $\boldsymbol{\alpha}_{1}=\boldsymbol{\beta}_{01}+\left(\frac{1}{2}-\frac{\gamma_{0} c_{0}}{4}-\frac{\gamma_{0}^{3} c_{0}^{3}}{96}\right) \boldsymbol{\beta}_{02}, \boldsymbol{\alpha}_{2}=$ $\left(\frac{\gamma_{0}}{4}+\frac{\gamma_{0}^{3} c_{0}^{2}}{32}\right) \boldsymbol{\beta}_{02}, \boldsymbol{\alpha}_{3}=-\frac{\gamma_{0}^{3} c_{0}}{32} \boldsymbol{\beta}_{02}$, and $\boldsymbol{\alpha}_{4}=\frac{\gamma_{0}^{3}}{96} \boldsymbol{\beta}_{02}$.

A new convenient null hypothesis is $\mathcal{H}_{0}: \boldsymbol{\alpha}_{2}=\boldsymbol{\alpha}_{3}=\boldsymbol{\alpha}_{4}=\mathbf{0}$. Note that 9 is a nonlinearin-variables regression model with endogenous regressors, as discussed in Davidson and MacKinnon (1993, pp. 224-226).

In order to derive the linearity test, consider the following notation. Set $\mathbf{y}$ as in Section 2, Define $\mathbf{g}\left(\mathbf{X} ; \boldsymbol{\psi}^{*}\right) \in \mathbb{R}^{T}$ as a vector with typical line given by the function

$$
g\left(\mathbf{x}_{t} ; \boldsymbol{\psi}^{*}\right)=\left(\boldsymbol{\alpha}_{1}^{\prime} \widetilde{\mathbf{x}}_{t}+\boldsymbol{\alpha}_{2}^{\prime} \widetilde{\mathbf{x}}_{t} s_{t}+\boldsymbol{\alpha}_{3}^{\prime} \widetilde{\mathbf{x}}_{t} s_{t}^{2}+\boldsymbol{\alpha}_{4}^{\prime} \widetilde{\mathbf{x}}_{t} s_{t}^{3}\right)
$$

where $\boldsymbol{\psi}^{*}=\left(\boldsymbol{\alpha}_{1}^{\prime}, \boldsymbol{\alpha}_{2}^{\prime}, \boldsymbol{\alpha}_{3}^{\prime}, \boldsymbol{\alpha}_{4}^{\prime}\right)^{\prime}$. Furthermore, set the restricted and unrestricted parameter estimates as $\widehat{\boldsymbol{\psi}}_{r}^{*}=\left(\widehat{\boldsymbol{\alpha}}_{1}^{\prime}, \mathbf{0}^{\prime}, \mathbf{0}^{\prime}, \mathbf{0}^{\prime}\right)^{\prime}$ and $\widehat{\boldsymbol{\psi}}_{u}^{*}=\left(\widehat{\boldsymbol{\alpha}}_{1}^{\prime}, \widehat{\boldsymbol{\alpha}}_{2}^{\prime}, \widehat{\boldsymbol{\alpha}}_{3}^{\prime}, \widehat{\boldsymbol{\alpha}}_{4}^{\prime}\right)^{\prime}$, respectively. Finally, set $\mathbf{P}_{Z}=\mathbf{Z}\left(\mathbf{Z}^{\prime} \mathbf{Z}\right)^{-1} \mathbf{Z}^{\prime}$, where $\mathbf{Z}$ is a $\left(T \times q_{z}\right), q_{z} \geq K$, matrix of valid instruments, as in Section 2, formed by linear and/or nonlinear functions of the exogenous variables, $\mathbf{w}_{t}$.

The linearity test is equivalent to an F-test in a instrumental variables regression and can be carried out in stages, as follows (see Davidson and MacKinnon (1993, pp. 226-232) for a discussion):

(1) Estimate (9) under the null and compute $S S R_{r}=\left\|\mathbf{P}_{Z}\left[\mathbf{y}-\mathbf{g}\left(\mathbf{x}_{t} ; \widehat{\boldsymbol{\psi}}_{r}^{*}\right)\right]\right\|^{2}$.

(2) Estimate the unrestricted model (9) and compute $S S R_{u}=\left\|\mathbf{P}_{Z}\left[\mathbf{y}-\mathbf{g}\left(\mathbf{x}_{t} ; \widehat{\boldsymbol{\psi}}_{u}^{*}\right)\right]\right\|^{2}$.

(3) Compute the statistid5

$$
\mathrm{F}=\frac{\left(S S R_{r}-S S R_{u}\right) / k}{\left\|\mathbf{y}-\mathbf{g}\left(\widehat{\boldsymbol{\psi}}_{u}^{*}\right)\right\|^{2} /[T-k]}
$$

Under the null hypothesis, the statistic $\mathrm{F}$ is asymptotically distributed as an $\mathrm{F}$ distribution with $k$ and $T-k$ degrees of freedom, where $k$ is the number of restrictions tested.

\footnotetext{
${ }^{4}$ If $s_{t}$ is an element of $\mathbf{x}_{t}$, then the resulting model should be

$$
y_{t}=\boldsymbol{\alpha}_{1}^{\prime} \widetilde{\mathbf{x}}_{t}+\boldsymbol{\alpha}_{2}^{\prime} \mathbf{x}_{t} s_{t}+\boldsymbol{\alpha}_{3}^{\prime} \mathbf{x}_{t} s_{t}^{2}+\boldsymbol{\alpha}_{2}^{\prime} \mathbf{x}_{t} s_{t}^{3}+u_{t}^{*}
$$
}

${ }^{5}$ If $s_{t}$ is an element of $\mathbf{x}_{t}$, then

$$
\mathrm{F}=\frac{\left.\left(S S R_{r}-S S R_{u}\right) / k\right)}{\left\|\mathbf{y}-\mathbf{g}\left(\widehat{\psi}_{u}^{*}\right)\right\|^{2} /[T-k]}
$$


In equation (9) the regressors are products of the endogenous variables, and the optimal set of instruments, as discussed in Amemiya (1975), is formed by power functions of the exogenous variables. For example, suppose that

$$
\mathbf{x}_{t}=\left(\begin{array}{c}
\mathbf{x}_{L, t} \\
s_{t}
\end{array}\right)=\left(\begin{array}{cc}
\boldsymbol{\theta}_{x}^{\prime} & 0 \\
0 & \theta_{s}
\end{array}\right)\left(\begin{array}{c}
\mathbf{w}_{x, t} \\
w_{s, t}
\end{array}\right)+\left(\begin{array}{c}
\mathbf{v}_{x, t} \\
v_{s, t}
\end{array}\right) .
$$

In this case, the optimal set of instruments is $\mathbf{z}_{t}=\left(1, \mathbf{w}_{x, t}^{\prime}, \mathbf{w}_{x, t}^{\prime} w_{s, t}, \mathbf{w}_{x, t}^{\prime} w_{s, t}^{2}, \mathbf{w}_{x, t}^{\prime} w_{s, t}^{3}\right)^{\prime}$. It is important that the same set of instruments is used in each step of the procedure described above.

\section{PARAMETER Estimation}

5.1. Main Results. In this paper we consider two methods to estimate the STR model with endogenous covariates. The first one is the GMM estimator as in (3). The second one is the modified nonlinear IV estimator defined in (6).

When the transition variable is exogenous, the reduced form for $y_{t}$ can be written as

$$
y_{t}=\boldsymbol{\pi}_{01}^{\prime} \widetilde{\mathbf{w}}_{t}+\boldsymbol{\pi}_{02}^{\prime} \widetilde{\mathbf{w}}_{t} f\left(s_{t} ; \gamma_{0}, c_{0}\right)+\xi_{t},
$$

where $\widetilde{\mathbf{w}}_{t}=\left(1, \mathbf{w}_{t}\right)^{\prime}$, with $\widetilde{\mathbf{x}}_{t}=\widetilde{\boldsymbol{\Theta}}_{0} \widetilde{\mathbf{w}}_{t}+\widetilde{\mathbf{v}}_{t}, \widetilde{\mathbf{v}}_{t}=\left(0, \mathbf{v}_{t}^{\prime}\right)^{\prime}, \boldsymbol{\pi}_{01}=\widetilde{\boldsymbol{\Theta}}_{0} \boldsymbol{\beta}_{01}, \boldsymbol{\pi}_{02}=\widetilde{\boldsymbol{\Theta}}_{0} \boldsymbol{\beta}_{02}$, and the error term is given by $\xi_{t}=u_{t}+\boldsymbol{\beta}_{02}^{\prime} \widetilde{\mathbf{v}}_{t} f\left(s_{t} ; \gamma_{0}, c_{0}\right)$. It is clear that, under Assumption $4 \mathbb{E}\left[\xi_{t} \widetilde{\mathbf{w}}_{t} f\left(s_{t} ; \gamma_{0}, c_{0}\right)\right]=$ 0 and the parameters of (11) can be estimated by nonlinear least-squares. Furthermore, $\gamma_{0}$ and $c_{0}$ are both identified. This fact opens the possibility of two-step estimation: first compute estimates $\widehat{\gamma}$ and $\widehat{c}$ for $\gamma_{0}$ and $c_{0}$, respectively, using (11), than substitute $\widehat{\gamma}$ and $\widehat{c}$ in (7) and estimate $\boldsymbol{\beta}_{01}$ and $\boldsymbol{\beta}_{02}$. One advantage is that, given $\widehat{\gamma}$ and $\widehat{c}$, the STR model becomes a nonlinear-in-variables model. This is the spirit of the estimator proposed by Caner and Hansen (2004). Here we take a different route by considering a possibly endogenous transition variable.

The following theorem follows directly from Theorem 8.1.1 in Amemiya (1985, p. 246).

THEOREM 1 (Consistency). Under Assumptions 2 $5 \widehat{\boldsymbol{\psi}}_{G M M} \stackrel{p}{\longrightarrow} \boldsymbol{\psi}_{0}$ and $\widehat{\boldsymbol{\psi}}_{M I V} \stackrel{p}{\longrightarrow} \boldsymbol{\psi}_{0}$.

In order to state the asymptotic normality result, we have to consider an additional assumption.

ASSUMPTION 8 (Asymptotic Normality). $\frac{1}{T} \mathbf{Z}^{\prime} \frac{\partial^{2} \mathbf{g}(\mathbf{X} ; \boldsymbol{\psi})}{\partial \psi_{i} \partial \boldsymbol{\psi}^{\prime}}$ converges in probability uniformly in $\boldsymbol{\psi} \in$ $N\left(\psi_{0}\right)$, where $\psi_{i}$ is the ith element of $\boldsymbol{\psi}$.

THEOREM 2 (Asymptotic Normality). Under Assumptions 2 [ 8

$$
\sqrt{T}\left(\widehat{\boldsymbol{\psi}}_{G M M}-\boldsymbol{\psi}_{0}\right) \stackrel{d}{\longrightarrow} \mathrm{N}\left(\mathbf{0}, \sigma_{0} \mathbf{A}_{G M M}^{-1}\right),
$$

where

$$
\mathbf{A}_{G M M}=\mathbb{E}\left[\dot{\mathbf{g}}\left(\mathbf{X} ; \boldsymbol{\psi}_{0}\right)^{\prime} \mathbf{P}_{Z} \dot{\mathbf{g}}\left(\mathbf{X} ; \boldsymbol{\psi}_{0}\right)\right]
$$

Furthermore,

$$
\sqrt{T}\left(\widehat{\boldsymbol{\psi}}_{M I V}-\boldsymbol{\psi}_{0}\right) \stackrel{d}{\longrightarrow} \mathrm{N}\left(\mathbf{0}, \sigma_{0} \mathbf{A}_{M I V}^{-1}\right),
$$

where

$$
\mathbf{A}_{M I V}=\mathbb{E}\left\{\mathbf{G}^{-1}\left[\sigma_{*}^{2} \mathbf{G}+\left(\sigma_{0}^{2}-\sigma_{*}^{2}\right) \mathbf{H}\right] \mathbf{G}^{-1}\right\}
$$




$$
\begin{gathered}
\mathbf{G}=\dot{\mathbf{g}}\left(\mathbf{X} ; \boldsymbol{\psi}_{0}\right)^{\prime}\left[\mathbf{I}-\mathbf{v}\left(\mathbf{v}^{\prime} \mathbf{v}\right)^{-1} \mathbf{v}^{\prime}\right] \dot{\mathbf{g}}\left(\mathbf{X} ; \boldsymbol{\psi}_{0}\right), \\
\mathbf{v}=\left(\mathbf{v}_{1}, \ldots, \mathbf{v}_{T}\right)^{\prime}, \sigma_{*}^{2}=\sigma_{0}^{2}-\boldsymbol{\Sigma}_{u v}^{\prime} \boldsymbol{\Sigma}_{v} \boldsymbol{\Sigma}_{u v}, \text { and } \\
\mathbf{H}=\dot{\mathbf{g}}\left(\mathbf{X} ; \boldsymbol{\psi}_{0}\right)^{\prime} \mathbf{P}_{Z} \dot{\mathbf{g}}\left(\mathbf{X} ; \boldsymbol{\psi}_{0}\right) .
\end{gathered}
$$

5.2. The Choice of Instruments. Set $f_{t, 0} \equiv f\left(s_{t} ; \gamma_{0}, c_{0}\right)$. Hence,

$$
\begin{aligned}
\dot{\mathbf{g}}\left(\mathbf{x}_{t} ; \boldsymbol{\psi}_{0}\right) & =\left[\left.\frac{\partial g\left(\mathbf{x}_{t} ; \boldsymbol{\psi}\right)}{\partial \boldsymbol{\beta}_{1}^{\prime}}\right|_{\boldsymbol{\psi}=\boldsymbol{\psi}_{0}},\left.\frac{\partial g\left(\mathbf{x}_{t} ; \boldsymbol{\psi}\right)}{\partial \boldsymbol{\beta}_{2}^{\prime}}\right|_{\boldsymbol{\psi}=\boldsymbol{\psi}_{0}},\left.\frac{\partial g\left(\mathbf{x}_{t} ; \boldsymbol{\psi}\right)}{\partial \gamma}\right|_{\boldsymbol{\psi}=\boldsymbol{\psi}_{0}},\left.\frac{\partial g\left(\mathbf{x}_{t} ; \boldsymbol{\psi}\right)}{\partial c}\right|_{\boldsymbol{\psi}=\boldsymbol{\psi}_{0}}\right]^{\prime} \\
& =\left[\widetilde{\mathbf{x}}_{t}^{\prime}, \widetilde{\mathbf{x}}_{t}^{\prime} f_{t, 0}, \boldsymbol{\beta}_{20}^{\prime} \widetilde{\mathbf{x}}_{t} f_{t, 0}\left(1-f_{t, 0}\right)\left(s_{t}-c_{0}\right),-\boldsymbol{\beta}_{20}^{\prime} \widetilde{\mathbf{x}} f_{t, 0}\left(1-f_{t, 0}\right) \gamma_{0}\right]^{\prime} .
\end{aligned}
$$

It is clear that the gradient depends on the structural parameters. In order to compute the "optimal" instruments as in (4), we adopt the following procedure:

(1) Start from an initial and consistent estimate of $\psi_{0}$, say $\widehat{\boldsymbol{\psi}}$. For example, consider estimators of type (3) or (6) with any set of valid instruments. Compute $\dot{\mathbf{g}}\left(\mathrm{x}_{t} ; \widehat{\boldsymbol{\psi}}\right)$.

(2) Regress $\dot{\mathbf{g}}\left(\mathbf{x}_{t} ; \widehat{\boldsymbol{\psi}}\right)$ on $\mathbf{w}_{t}$ and on the powers and cross-products of the elements of $\mathbf{w}_{t}$. Compute $\dot{\mathrm{g}}\left(\mathrm{x}_{t} ; \widehat{\boldsymbol{\psi}}\right)$.

(3) Set $\mathbf{z}_{t}=\dot{\mathbf{g}}\left(\mathbf{x}_{t} ; \widehat{\boldsymbol{\psi}}\right)$ and re-estimate the parameters.

As mentioned in Section 2. Newey (1990) showed that the procedure above can be seen as a series nonparametric approximation to (4). He also proved that this procedure yields efficient estimation in an IID framework. The optimality of such a procedure in a time series context is yet to be proved, but this is beyond the scope of the paper.

\section{Model Evaluation}

The goal of this section is to discuss a number of misspecification tests for STR models with parameters estimated by moment-based techniques such the ones previously described. One natural diagnostic test is the $J$-test for overidentifying conditions proposed by Hansen (1982). Another set of useful tests can be developed on the basis of Gauss-Newton regressions (GNR), as discussed in Davidson and MacKinnon (1993, pp. 226-232).

Define $\widehat{u_{t}}=y_{t}-g\left(\mathbf{x}_{t} ; \widehat{\boldsymbol{\psi}}\right)$ and consider the following GNR:

$$
\widehat{u}_{t}=\mathbf{P}_{Z} \dot{\mathbf{g}}\left(\mathbf{x}_{t} ; \widehat{\boldsymbol{\psi}}\right) \mathbf{b}+e_{t},
$$

where $\left\{e_{t}\right\}$ is a sequence of errors and $\widehat{\boldsymbol{\psi}}$ is any consistent estimator of $\boldsymbol{\psi}_{0}$. As observed in Davidson and MacKinnon (1993), the ordinary least squares (OLS) estimate of $\mathbf{b}$ must be zero and this fact can be used as a measure of the accuracy of the nonlinear optimization routine employed. Thus, testing $\mathcal{H}_{0}: \mathbf{b}=\mathbf{0}$ in (13) is a very simple diagnostic check.

Another useful diagnostic is to augment equation (13) with nonlinear terms and test for neglected nonlinearity, such as additional regimes. For example, we can consider the following GNR:

$$
\widehat{u}_{t}=\mathbf{P}_{Z} \dot{\mathbf{g}}\left(\mathbf{x}_{t} ; \widehat{\boldsymbol{\psi}}\right) \mathbf{b}+\boldsymbol{\alpha}_{1}^{\prime} \mathbf{x}_{t} s_{t}+\boldsymbol{\alpha}_{2}^{\prime} \mathbf{x}_{t} s_{t}^{2}+\boldsymbol{\alpha}_{3}^{\prime} \mathbf{x}_{t} s_{t}^{3}+e_{t},
$$


and test $\mathcal{H}_{0}: \boldsymbol{\alpha}_{1}=\boldsymbol{\alpha}_{2}=\boldsymbol{\alpha}_{3}=\mathbf{0}$. The resulting procedure is a simple F-test in an OLS regression.

\section{Monte CARLo EXPERIMENT}

The goal of this section is to evaluate the finite sample performance of the linearity test. Two different DGPs will be used, and they are defined as follows:

(1) Model A: IID observations

$$
\begin{aligned}
& y_{t}=-0.2+1.4 x_{t}+\left(0.6-2.3 x_{t}\right) f\left(x_{t} ; \gamma_{0},-2.0\right)+u_{t}, \\
& x_{t}=\theta w_{t}+v_{t},
\end{aligned}
$$

where $\gamma_{0}=0$ or $10, u_{t}=v_{t}+e_{t}, v_{t} \sim \operatorname{NID}(0,1), e_{t} \sim \operatorname{NID}(0,1)$, and $w_{t} \sim \operatorname{NID}(0,1)$.

(2) Model B: Weakly dependent observations

$$
\begin{aligned}
& y_{t}=-0.2+1.4 x_{t}+\left(0.6-2.3 x_{t}\right) f\left(x_{t} ; \gamma_{0},-2.0\right)+u_{t}, \\
& x_{t}=\theta w_{t}+v_{t}, \\
& w_{t}=0.8 w_{t-1}+\xi_{t}
\end{aligned}
$$

where $\gamma_{0}=0$ or $10, u_{t}=v_{t}+e_{t}, v_{t} \sim \operatorname{NID}(0,1), e_{t} \sim \operatorname{NID}(0,1)$, and $\xi_{t} \sim \operatorname{NID}(0,1)$.

Both models have a single endogenous variable, $x_{t}$, that is also the transition variable. The data generated from Model A are independent and identically distributed. Model B generated weakly dependent data as $w_{t}$ is a linear autoregressive (AR) model. We generate 2000 replications of each model with 100, 250, and 500 observations. Models with $\gamma_{0}=0$ will be useful to evaluate the empirical size of the linearity test.

As discussed in Section 4, linearity testing involves the estimation of a model with endogenous variables that are linear in the parameters but nonlinear in the variables. This type of specification and estimation has been considered in the literature since Kelejian (1971). The optimal choice of instruments has been discussed in several papers, as mentioned in Section 2 . Here we will focus on estimators as in (3). For both models, the set of instruments is $\mathbf{z}_{t}=\left(1, w_{t}, w_{t}^{2}, w_{t}^{3}, w_{t}^{4}\right)^{\prime}$. Our choice of instruments is quite natural as the regressors in the test equations are powers of the endogenous variables (see equation 9).

We consider different values for the parameter $\theta$ in both models in order to evaluate the strength of the set of instruments. The higher the value of $\theta$, the stronger are the instruments. For example, when Model A is considered, the correlation between $x_{t}$ and $w_{t}$ is given by $\rho_{x, w}=\frac{\theta}{\sqrt{1+\theta^{2}}}$. Clearly, the correlation between powers of $x_{t}$ and $w_{t}$ will be also function of $\theta$.

The linearity test results for Model A are presented in Figures 1 and 2, We report both the empirical size and power of the linearity test for 100 observations and a nominal significance level of 0.05 . When $\theta$ is close to zero (the set of instruments is not valid), the test is heavily undersized. On the other hand, the empirical size approaches the nominal size as $\theta$ increases (the instruments are quite strong). This fact highlights the harmful influence of weak instruments on the performance of the linearity test. However, it seems that the power of test is less affected by the strength of the instruments. 


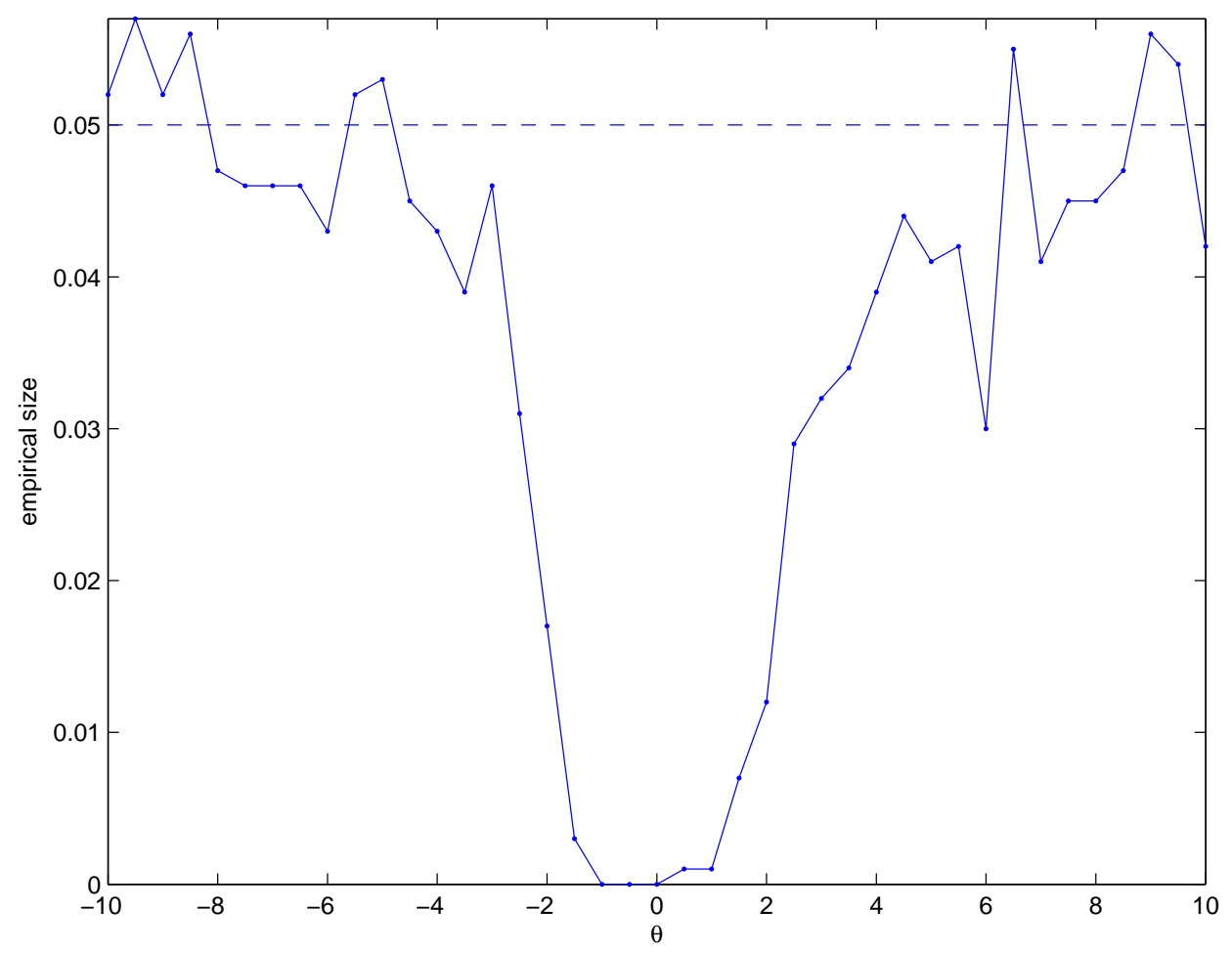

FIGURE 1. Empirical size of the linearity test (Model A) across different values of $\theta$. The nominal significance level is 0.05 and the number of observations is 100 .

The results concerning Model B are shown in Figures 3 and 4 As in the previous case, the linearity test is undersized, specially when $\theta$ is near zero and approaches the nominal one as $\theta$ increase in absolute value. The power of the test goes to one as $\theta$ increases in absolute value.

Tables 1 and 2 show the estimation results. The parameters of Models A and B are estimated by the modified nonlinear IV estimator as (6). The nonlinear IV estimator (3) was also used but, as the estimates are less precise and have large outliers, we will show only the results concerning the modified estimator. We report results for 100, 250, and 500 observations. We consider only the case where $\theta=1$.

As can be seen by inspection of Tables 1 and 2 , apart from $\gamma$, all the other parameters are estimated quite well and the precision improves, as expected, as the sample size increases. Skewness approaches 0 (symmetric distribution) and the kurtosis coefficient tends to 3 as the sample size increases, indicating convergence of the estimator to a normally distributed random variable. Finally, although, on average, the estimates of $\gamma$ are much higher than the true value, this is caused mainly by a few extreme observations. When the median is used as a measure of central tendency, the results improve substantially.

\section{Application}

8.1. Inflation Targeting in Brazil. STR models have been successfully applied to describe the behavior of various macroeconomic time series (see, for example, van Dijk, Teräsvirta, and Franses (2002)). In 


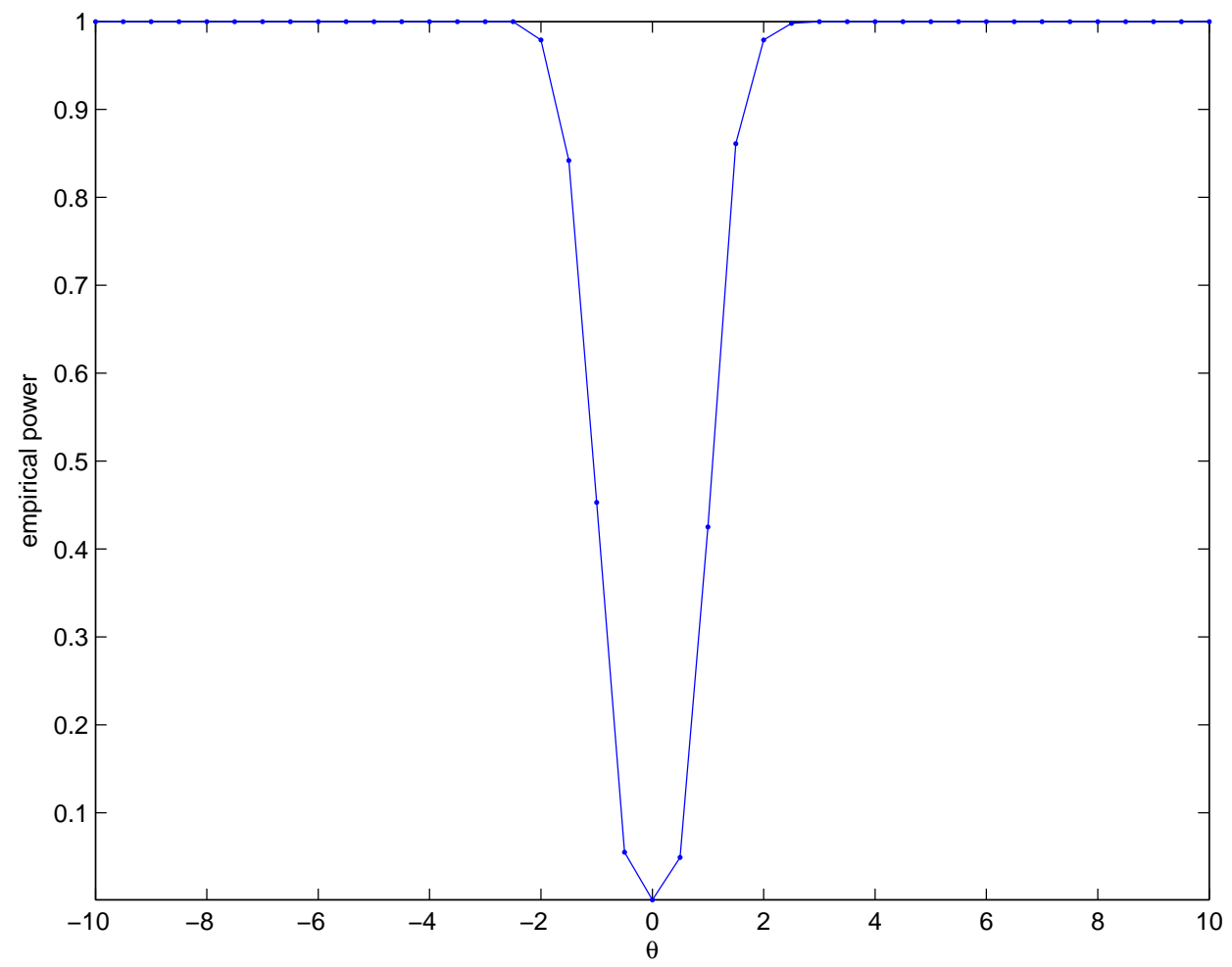

FIGURE 2. Empirical power of the linearity test (Model A) across different values of $\theta$. The nominal significance level is 0.05 and the number of observations is 100 .

this section, we analyze the Brazilian inflation rate series after the adoption of inflation targeting (IT) in mid-1999 to illustrate the modeling cycle for STR models.

Since the early 1990s, a growing number of central banks in industrial and emerging countries have considered the adoption of an IT framework, including the USA. The IT literature points out that much of its benefits can be attributed to its impact on inflation expectations. Woodford (2004) argues that the most important achievement of inflation-targeting central banks has not been the reorientation of the goals of monetary policy toward a stronger emphasis on controlling inflation, but rather the development of an approach to the conduct of policy that focuses on a clearly defined target. Accordingly, one important advantage of commitment to an appropriately chosen policy rule is that it facilitates public understanding of policy, which is crucial in order for monetary policy to be most effective?

This seems to be the case in Brazil. As noted by Cerisola and Gelos (2005), the adoption of an explicit and public target for inflation influenced the expectations of private agents. The authors examine the macroeconomic determinants of survey inflation expectations in Brazil since the adoption of inflation targeting in 1999. The results suggest that the inflation targeting framework has helped anchor

\footnotetext{
${ }^{6}$ See Mishkin and Schmidt-Hebbel (2001) for a survey of early experiences with inflation targeting. Ball and Sheridan (2003) present a more pessimistic view from experience to date.

${ }^{7}$ In Woodford's (2004, p. 16) own words: "For not only do expectations about policy matter, but, at least under current conditions, very little else matters."
} 


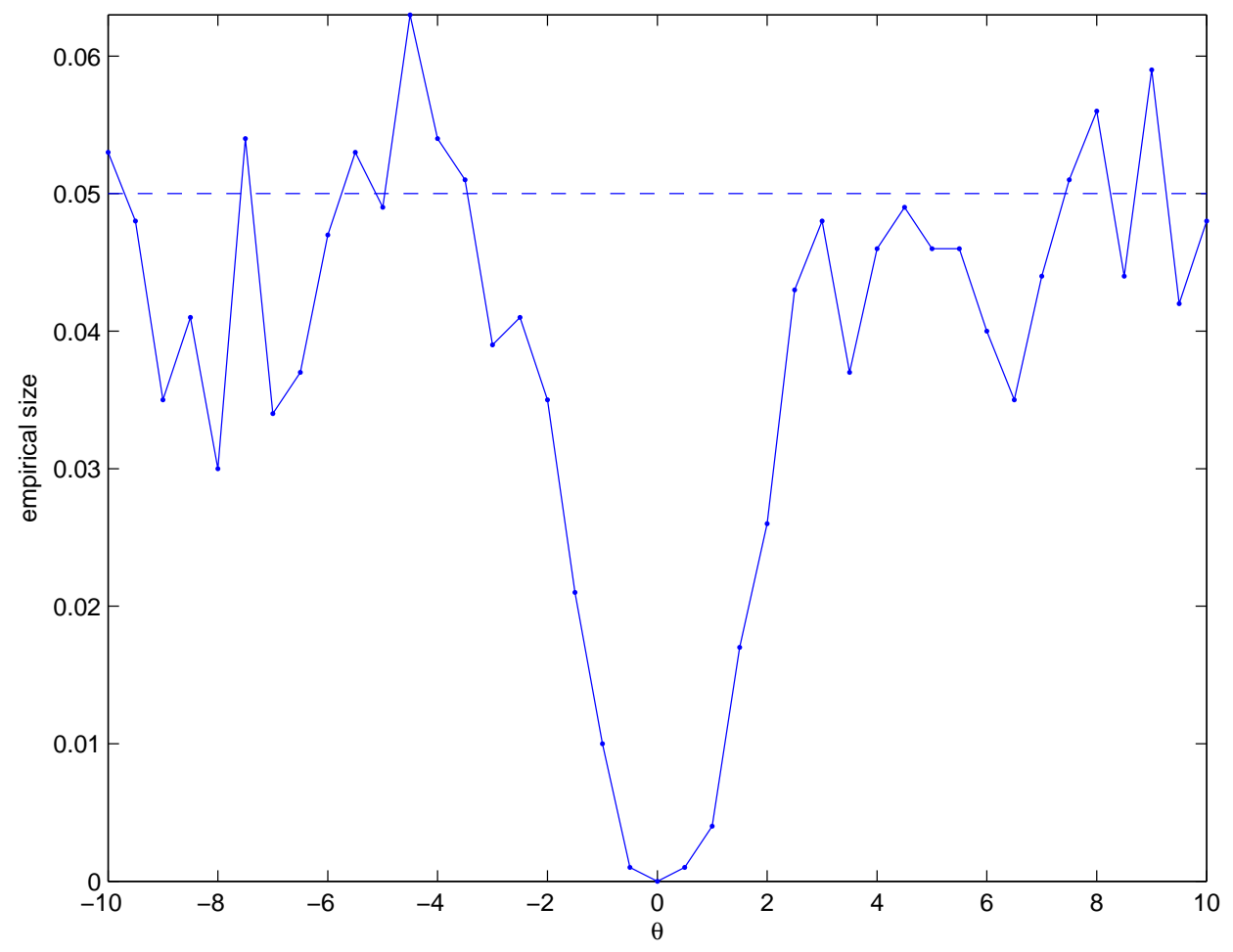

FIgURE 3. Empirical size of the linearity test (Model B) across different values of $\theta$. The nominal significance level is 0.05 and the number of observations is 100 .

expectations, with the dispersion of inflation expectations declining considerably. They also find that the inflation target has been instrumental in shaping expectations while the importance of past inflation in determining expectations appears to be relatively low.

Soon after changing to a floating exchange rate regime in 1999, Brazil adopted an explicit inflation targeting framework as part of an extensive program of economic reforms. This development ended a period during which the exchange rate had been the main anchor for monetary policy. The mounting uncertainties after the floating of the Real in early 1999 enticed the implementation of a more strict inflation targeting framework, one that would represent a firm commitment to prevent inflation from getting out of control. Moreover, the relatively loose fiscal stance at the outset of the new regime, as well as the lack of formal operational autonomy of the Central Bank, presented additional challenges to the conduct of monetary policy, in particular to the construction of credibility.

In order to deal with these concerns, the Central Bank has adopted a flexible and accountable approach in conducting policy. For instance, even when the targets were breached and revised, the process was undertaken in a very transparent manner through open letters from the Central Bank. As noted in Mishkin (2004), the role of the Central Bank in this accomplishment provides a good example for other emerging markets considering adopting inflation targeting: the way the Central Bank articulated the reasons why 


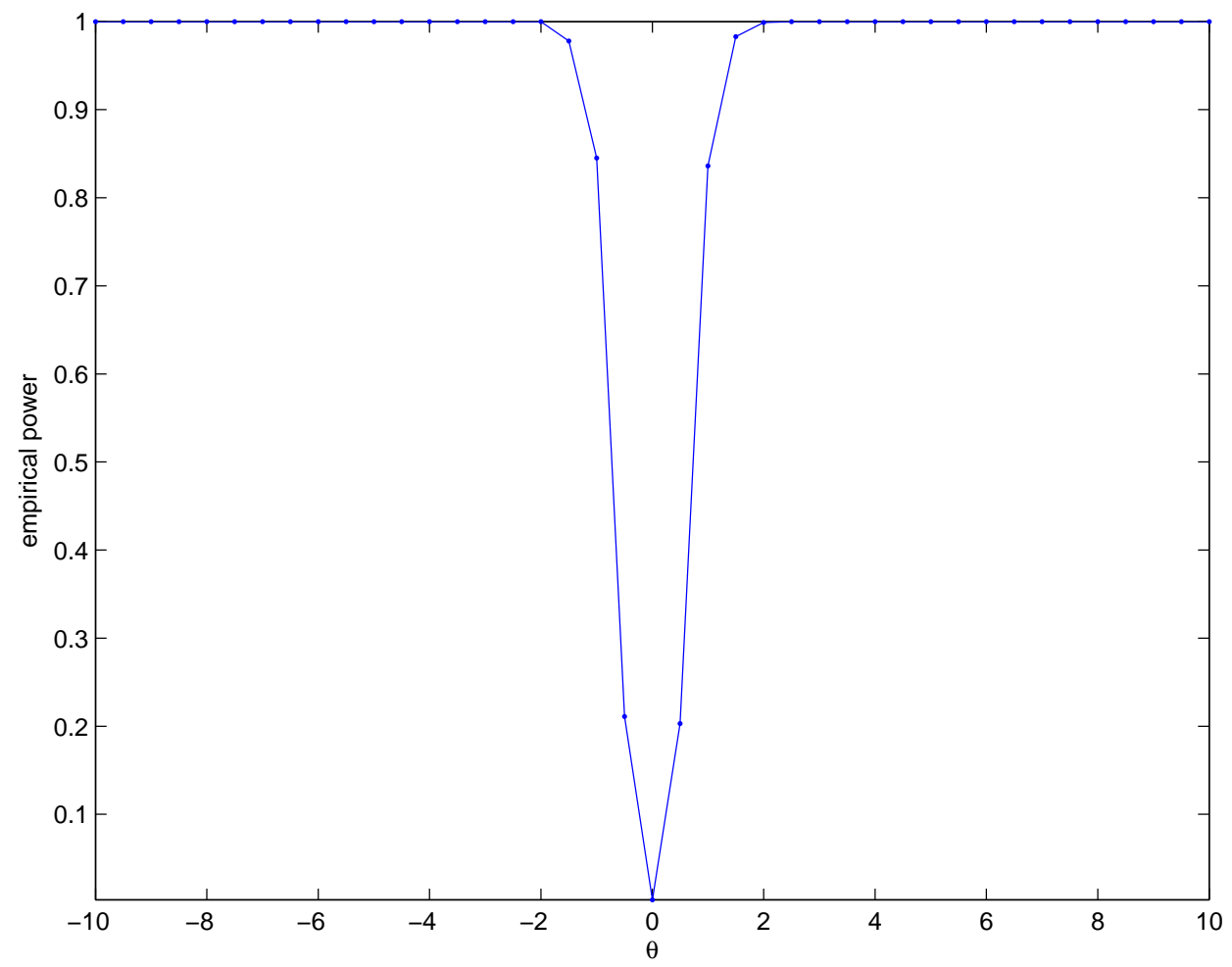

FIGURE 4. Empirical power of the linearity test (Model B) across different values of $\theta$. The nominal significance level is 0.05 and the number of observations is 100 .

the initial inflation target was missed, how it responded to the shock, and how it planned to return to its longer-run inflation goal.

The new regime has been tested in a number of different ways during its short lifetime, with the intensity and frequency of shocks being unprecedented. Despite challenging conditions, the new monetary framework has proved to be an effective guide for expectations. Even when current inflation deviated from the established targets, monetary policy under inflation target was, for much of the time, capable of keeping inflation expectations in line with the official inflation targets. In the following section, we will formally analyze how the adoption of an explicit target for inflation affects inflation dynamics and monetary policy.

8.2. Analytical Framework for the Inflation Process: The Phillips Curve. The standard approach to characterize the inflation process is some kind of Phillips Curve relation. Specifically, the so-called "New-Keynesian" Phillips curve (NKPC) is simply a log-linear approximation about the steady state of the aggregation of the individual firm pricing decisions and relates inflation positively to the output gap 8

$$
\pi_{t}=\beta_{1} x_{t}+\beta_{2} \mathbb{E}_{t} \pi_{t+1}+u_{t}
$$

\footnotetext{
${ }^{8}$ The model of nominal rigidities proposed by Calvo (1993) was used in this case.
} 
TABle 1. Monte Carlo Simulations: Parameter Estimates for Model A.

The table shows the mean, median, standard deviation, skewness and kurtosis for each parameter estimate over 2000 replications for different sample sizes. The parameters are estimated minimizing (6) as proposed in Amemiya (1975). The instruments used are $\mathbf{z}_{t}=$ $\left(1, w_{t}, w_{t}^{2}, w_{t}^{3}, w_{t}^{4}, w_{t}^{5}\right)^{\prime}$.

\begin{tabular}{|c|c|c|c|c|c|c|}
\hline \multicolumn{7}{|c|}{100 Observations } \\
\hline Parameter & True Value & Mean & Median & Std. Dev. & Skewness & Kurtosis \\
\hline$\beta_{11}$ & -0.2 & -0.34 & 0.11 & 5.09 & -0.55 & 5.11 \\
\hline$\beta_{12}$ & 1.4 & 1.43 & 1.58 & 1.81 & -0.24 & 6.00 \\
\hline$\beta_{21}$ & 0.6 & 0.75 & 0.23 & 5.10 & 0.56 & 5.15 \\
\hline$\beta_{22}$ & -2.3 & -2.31 & -2.41 & 1.79 & 0.21 & 5.94 \\
\hline$\gamma$ & 10 & 64.73 & 12.82 & 136.16 & 3.31 & 14.64 \\
\hline$c$ & -2 & -1.99 & -1.99 & 0.13 & 1.51 & 11.43 \\
\hline
\end{tabular}

\begin{tabular}{|c|c|c|c|c|c|c|}
\hline \multirow[b]{2}{*}{ Parameter } & \multicolumn{5}{|c|}{$\underline{250 \text { Observations }}$} & \multirow[b]{2}{*}{ Kurtosis } \\
\hline & True Value & Mean & Median & Std. Dev. & Skewness & \\
\hline$\beta_{11}$ & -0.2 & -0.29 & -0.08 & 2.50 & -1.61 & 10.46 \\
\hline$\beta_{12}$ & 1.4 & 1.40 & 1.48 & 0.86 & -1.41 & 9.40 \\
\hline$\beta_{21}$ & 0.6 & 0.69 & 0.44 & 2.51 & 1.63 & 10.51 \\
\hline$\beta_{22}$ & -2.3 & -2.29 & -2.36 & 0.85 & 1.35 & 9.20 \\
\hline$\gamma$ & 10 & 30.41 & 10.54 & 378.78 & 26.88 & 762.18 \\
\hline$c$ & -2 & -2.00 & -1.99 & 0.05 & -0.72 & 8.70 \\
\hline
\end{tabular}

\begin{tabular}{|c|c|c|c|c|c|c|}
\hline \multicolumn{7}{|c|}{500 Observations } \\
\hline Parameter & True Value & Mean & Median & Std. Dev. & Skewness & Kurtosis \\
\hline$\beta_{11}$ & -0.2 & -0.1491 & -0.1035 & 1.4219 & -0.3738 & 3.9481 \\
\hline$\beta_{12}$ & 1.4 & 1.4323 & 1.4626 & 0.4883 & -0.3935 & 4.1737 \\
\hline$\beta_{21}$ & 0.6 & 0.5507 & 0.4900 & 1.4258 & 0.3754 & 3.9228 \\
\hline$\beta_{22}$ & -2.3 & -2.3283 & -2.3536 & 0.4862 & 0.3295 & 4.0771 \\
\hline$\gamma$ & 10 & 10.9256 & 10.1493 & 3.8342 & 4.2906 & 46.0866 \\
\hline$c$ & -2 & -2.0005 & -1.9997 & 0.0338 & -0.2249 & 4.0112 \\
\hline
\end{tabular}

where $x_{t}$ is the output gap, $\pi_{t}$ is the inflation rate, $\mathbb{E}_{t} \pi_{t+1} \equiv \mathbb{E}\left(\pi_{t+1} \mid \mathcal{F}_{t}\right)$ is expected future inflation conditional on the information set available at time $t$, and $u_{t}$ is a cost-push shock.

Although theoretically appealing, this curve has problems when faced with the facts, specifically because of the absence of any endogenous persistence. In order to deal with this limitation, Galí and Gertler (1999) propose a model where a fraction of the firms use a cost-free rule-of-thumb based on lagged inflation to readjust their prices. The resulting equation is

$$
\pi_{t}=\beta_{1} \pi_{t-1}+\beta_{2} x_{t}+\beta_{3} \mathbb{E}_{t} \pi_{t+1}+u_{t} .
$$

Even if the central bank stabilizes the output gap from now on, the same would not occur with current inflation as it is influenced by its own recent history. Alves and Areosa (2005) argue that in an inflation targeting economy, it is natural to assume that pricing decisions should also incorporate the inflation target. The authors propose the following extension:

$$
\pi_{t}-\pi_{t}^{*}=\beta_{1} x_{t}+\beta_{2} \mathbb{E}_{t}\left[\pi_{t+1}-\pi_{t+1}^{*}\right]+u_{t}
$$


TABLE 2. Monte Carlo Simulations: Parameter Estimates for Model B.

The table shows the mean, median, standard deviation, skewness and kurtosis for each parameter estimate over 2000 replications for different sample sizes. The parameters are estimated minimizing (6) as proposed in Amemiya (1975). The instruments used are $\mathbf{z}_{t}=$ $\underline{\left(1, w_{t}, w_{t}^{2}, w_{t}^{3}, w_{t}^{4}, w_{t}^{5}\right)^{\prime} .}$

\begin{tabular}{|c|c|c|c|c|c|c|}
\hline \multicolumn{7}{|c|}{100 Observations } \\
\hline Parameter & True Value & Mean & Median & Std. Dev. & Skewness & Kurtosis \\
\hline$\beta_{11}$ & -0.2 & -0.39 & -0.29 & 1.51 & -0.92 & 8.45 \\
\hline$\beta_{12}$ & 1.4 & 1.36 & 1.40 & 0.46 & -1.01 & 9.08 \\
\hline$\beta_{21}$ & 0.6 & 0.80 & 0.66 & 1.54 & 1.11 & 8.67 \\
\hline$\beta_{22}$ & -2.3 & -2.25 & -2.27 & 0.43 & 0.65 & 9.79 \\
\hline$\gamma$ & 10 & 34.03 & 10.78 & 84.36 & 5.51 & 41.10 \\
\hline$c$ & -2 & -2.00 & -2.00 & 0.08 & -1.39 & 21.91 \\
\hline \multicolumn{7}{|c|}{$\underline{250 \text { Observations }}$} \\
\hline Parameter & True Value & Mean & Median & Std. Dev. & Skewness & Kurtosis \\
\hline$\beta_{11}$ & -0.2 & -0.14 & -0.13 & 0.68 & -0.21 & 4.52 \\
\hline$\beta_{12}$ & 1.4 & 1.41 & 1.42 & 0.20 & -0.74 & 7.21 \\
\hline$\beta_{21}$ & 0.6 & 0.54 & 0.52 & 0.68 & 0.32 & 4.62 \\
\hline$\beta_{22}$ & -2.3 & -2.31 & -2.32 & 0.18 & 0.34 & 5.71 \\
\hline$\gamma$ & 10 & 13.40 & 10.35 & 30.22 & 18.32 & 368.80 \\
\hline$c$ & -2 & -1.99 & -1.99 & 0.03 & -0.02 & 3.32 \\
\hline \multicolumn{7}{|c|}{$\underline{500 \text { Observations }}$} \\
\hline Parameter & True Value & Mean & Median & Std. Dev. & Skewness & Kurtosis \\
\hline$\beta_{11}$ & -0.2 & -0.20 & -0.20 & 0.43 & -0.09 & 3.78 \\
\hline$\beta_{12}$ & 1.4 & 1.39 & 1.40 & 0.12 & -0.24 & 3.68 \\
\hline$\beta_{21}$ & 0.6 & 0.60 & 0.60 & 0.44 & 0.17 & 3.81 \\
\hline$\beta_{22}$ & -2.3 & -2.29 & -2.30 & 0.11 & 0.10 & 3.49 \\
\hline$\gamma$ & 10 & 10.51 & 10.23 & 2.52 & 1.69 & 10.20 \\
\hline$c$ & -2 & -2.00 & -2.00 & 0.02 & -0.17 & 3.06 \\
\hline
\end{tabular}

with $\pi_{t}^{*}=(1-\lambda) \pi_{t-1}+\lambda \pi^{*}$, where $0<\lambda<1$ and $\pi^{*}$ is the inflation target.

The investigation of the presence of nonlinear mechanisms in the Phillips Curve has been an important topic in the recent literature because of its implications for monetary policy 9 Following a long tradition that goes back to Cukierman and Wachtel (1979) and Logue and Willett (1976), we argue that the level of inflation and the spread of expectations across individuals are positively related. Therefore, we consider the following family of nonlinear Phillips Curves:

$$
\begin{aligned}
\pi_{t}= & \bar{\pi}+\sum_{j=a}^{A} \beta_{1 j}^{L} \pi_{t-j}+\sum_{j=c}^{C} \beta_{2 j}^{L} x_{t-j}+\beta_{3}^{L} \mathbb{E}_{t} \tilde{\pi} \\
& +\left[\hat{\pi}+\sum_{j=a}^{A} \beta_{1 j}^{N} \pi_{t-j}+\sum_{j=c}^{C} \beta_{2 j}^{N} x_{t-j}+\beta_{3}^{N} \mathbb{E}_{t} \tilde{\pi}\right] f\left(\tilde{\sigma}_{t}^{\pi} ; \gamma, c\right)+u_{t},
\end{aligned}
$$

\footnotetext{
${ }^{9}$ See Schaling (1999), Laxton, Meredith, and Rose (1995), Eliasson (1999), Nobay and Peel (2000), and Musso, Stracca, and van Dijk (2007).
} 
where $\mathbb{E}_{t} \tilde{\pi}$ is a measure of future inflation expectations (measured as deviations from target inflation), $\sigma_{t}^{\pi}$ is a measure of expectations uncertainty, and $f\left(\tilde{\sigma}_{t k}^{\pi} ; \gamma, c\right)$ is the logistic function, as in (8).

In the STR model, the two regimes are associated with small and large values of the transition variable, $z_{t}$, relative to the location parameter, $c$. This type of regime-switching can be convenient for modeling asymmetric responses from a monopolistic price setter, where the regimes of the STR are related to the uncertainty of inflation expectations. The parameter $c$ can be interpreted as the tolerance level of uncertainty around the value that the price setter considers critical, and the parameter $\gamma$ determines the smoothness of the transition from one regime to the other.

8.3. Estimation. Now we examine whether there is evidence that the Brazilian inflation rate followed a nonlinear process between April 2000 and June 2007. The rationale is that the dynamic of inflation was different during periods of increased inflation uncertainty. We estimate linear and nonlinear models in order to compare the results. As both inflation expectations and expected inflation uncertainty are clearly endogenous, the nonlinear Phillips Curve proposed here is estimated by the nonlinear IV methods described above. Different sets of instruments are used in order to check the robustness of the results.

8.3.1. Data. The data source is Banco Central do Brasil (Central Bank of Brazil, hereafter BCB) and Ipea (Research Institute in Applied Economics) 10. As a measure of the annualized monthly inflation rate, $\pi_{t}$, we consider the Brazilian broad consumer price index (IPCA), used to gauge Brazilian inflation targets. The output gap, $x_{t}$, is measured by de-trended seasonally adjusted industrial production 11 Inflation expectations are obtained from a daily survey that the BCB conducts among financial institutions and consulting firms. The survey asks what firms expect for end-of-year inflation in the current and in the following years. The BCB discloses the mean, the median and the standard deviation of the inflation expectations. Our measure of inflation expectation is the median of the expectations across agents. Expected inflation uncertainty is the standard deviation of the inflation expectation across agents.

The Brazilian inflation-targeting regime sets year-end inflation targets for the current and the following two years. As it is necessary to have a single measurement of the deviation of inflation from the target, we use a weighted average of current and following years expected deviation of inflation from the target, where the weights are inversely proportional to the number of months remaining until the end of the year. Formally:

$$
\begin{aligned}
\mathbb{E}_{t} \tilde{\pi} & =\frac{m_{t}}{12} \times\left[\mathbb{E}_{t} \pi_{(0)}-\pi_{(0)}^{*}\right]+\left(\frac{12-m_{t}}{12}\right) \times\left[\mathbb{E}_{t} \pi_{(1)}-\pi_{(1)}^{*}\right], \\
\tilde{\sigma}_{t}^{\pi} & =\frac{m_{t}}{12} \times \sigma_{t,(0)}^{\pi}+\left(\frac{12-m_{t}}{12}\right) \times \sigma_{t,(1)}^{\pi},
\end{aligned}
$$

where $m_{t}$ is the number of months remaining until the end of the current year, $\mathbb{E}_{t} \pi_{(0)}$ and $\mathbb{E}_{t} \pi_{(1)}$ are, respectively, the expected inflation for the current and following years, and $\sigma_{t,(0)}^{\pi}$ and $\sigma_{t,(1)}^{\pi}$ are the standard deviations of of the inflation expectations for the current and upcoming years, respectively.

\footnotetext{
$\overline{10}$ All series are available at www.bcb.gov.br and www.ipeadata.gov.br

${ }^{11}$ Carneiro (2000) showed that linear de-trending is a reasonable strategy to compute the Brazilian output gap.
} 
(a) $\pi$

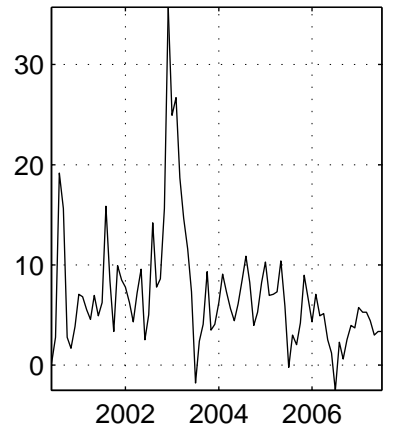

(d) $\sigma_{t}^{\pi}$

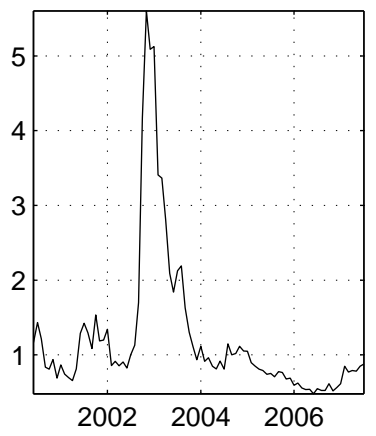

(b) $x$

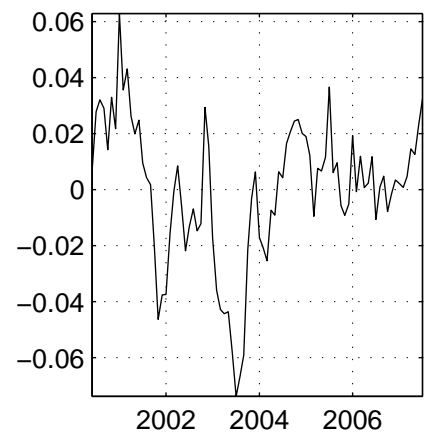

(e) $\Delta \mathrm{q}$

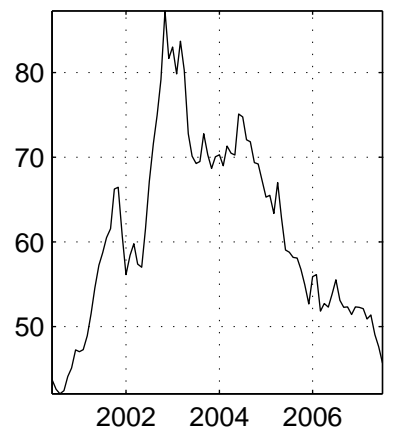

(c) $\mathrm{E} \pi$

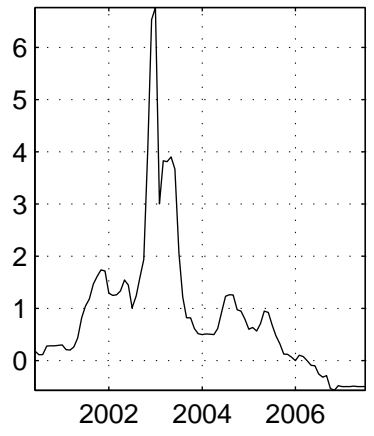

(f) $\Delta \mathrm{i}$

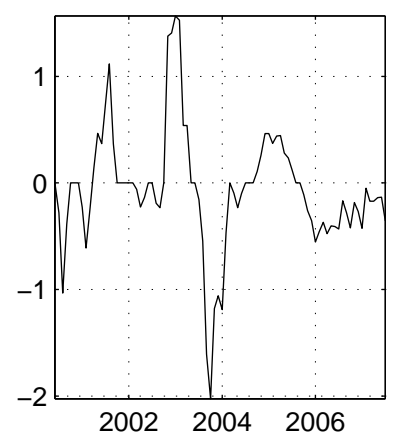

Figure 5. Variables used in the Phillips Curve.

Similarly, $\pi_{(0)}^{*}$ and $\pi_{(1)}^{*}$ are the targets for the current year and the following year, respectively. The values of $\tilde{\sigma}_{t}^{\pi}$ are normalized by the estimated unconditional standard deviation of the series.

Set $q_{t}$ as the real exchange rate and $i_{t}$ as the nominal interest rate given by the Selic rate, which is the Central Bank's primary monetary policy instrument. The Selic rate is the average interest rate on overnight inter-bank loans collateralized by government bonds that are registered with, and traded on, the Sistema Especial de Liquidação e Custódia (Selic). The Central Bank of Brazil Monetary Policy Committee (COPOM) establishes a target for the Selic interest rate and the Central Bank's open market desk executes regular liquidity management operations in the domestic money market, with the goal of keeping the daily Selic interest rate at the target level. Figure 1 illustrates the time evolution of the series used.

8.3.2. Estimates. First, we estimate the linear Phillips Curve:

$$
\pi_{t}=\bar{\pi}+\beta_{1} \pi_{t-1}+\beta_{2} x_{t-1}+\beta_{3} \mathbb{E}_{t} \tilde{\pi}+u_{t},
$$

where the error is assumed to be a martingal difference sequence, $\mathbb{E}\left(u_{t} \mid \mathcal{F}_{t-1}\right)=0$. We consider only the first lag of inflation and the output gap as residual analysis shows no evidence of remaining serial correlation. 
In order to estimate the model parameters, we consider the following choices for the exogenous variables, $\mathbf{w}_{t}$, and the set of instruments, $\mathbf{z}_{t}$ :

(1) Instruments set 1 (IS1):

$$
\begin{aligned}
\mathbf{w}_{t} & =\left(\pi_{t-1}, \ldots, \pi_{t-4}, x_{t-1}, x_{t-2}, \mathbb{E}_{t-1} \tilde{\pi}, \mathbb{E}_{t-2} \tilde{\pi}, \tilde{\sigma}_{t-1}^{\pi}, \tilde{\sigma}_{t-2}^{\pi}, \Delta i_{t-1}, \Delta i_{t-2}, \Delta q_{t-1}, \Delta q_{t-2}\right)^{\prime}, \\
\mathbf{z}_{t} & =\left(\pi_{t-1}, \ldots, \pi_{t-4}, x_{t-1}, x_{t-2}, \mathbb{E}_{t-1} \tilde{\pi}, \mathbb{E}_{t-2} \tilde{\pi}, \tilde{\sigma}_{t-1}^{\pi}, \tilde{\sigma}_{t-2}^{\pi}, \Delta i_{t-1}, \Delta i_{t-2}, \Delta q_{t-1}, \Delta q_{t-2}\right)^{\prime} .
\end{aligned}
$$

(2) Instruments set 2 (IS2):

$$
\begin{aligned}
\mathbf{w}_{t} & =\left(\pi_{t-1}, x_{t-1}, \mathbb{E}_{t-1} \tilde{\pi}, \tilde{\sigma}_{t-1}^{\pi}, \Delta i_{t-1}, \Delta q_{t-1}\right)^{\prime}, \\
\mathbf{z}_{t} & =\left(\pi_{t-1}, \pi_{t-1}^{2}, x_{t-1}, x_{t-1}^{2}, \mathbb{E}_{t-1} \tilde{\pi},\left(\mathbb{E}_{t-1} \tilde{\pi}\right)^{2}, \tilde{\sigma}_{t-1}^{\pi},\left(\tilde{\sigma}_{t-1}^{\pi}\right)^{2}, \Delta i_{t-1}, \Delta i_{t-1}^{2}, \Delta q_{t-1}, \Delta q_{t-1}^{2}\right)^{\prime} .
\end{aligned}
$$

(3) Instruments set 3 (IS3):

$$
\begin{aligned}
\mathbf{w}_{t} & =\left(\pi_{t-1}, \pi_{t-2}, x_{t-1}, x_{t-2}, \mathbb{E}_{t-1} \tilde{\pi}, \mathbb{E}_{t-2} \tilde{\pi}, \tilde{\sigma}_{t-1}^{\pi}, \tilde{\sigma}_{t-2}^{\pi}, \Delta i_{t-1}, \Delta i_{t-2}\right)^{\prime}, \\
\mathbf{z}_{t} & =\left(\pi_{t-1}, \pi_{t-2}, x_{t-1}, x_{t-2}, \mathbb{E}_{t-1} \tilde{\pi}, \mathbb{E}_{t-2} \tilde{\pi}, \tilde{\sigma}_{t-1}^{\pi}, \tilde{\sigma}_{t-2}^{\pi}, \Delta i_{t-1}, \Delta i_{t-2}\right)^{\prime} .
\end{aligned}
$$

(4) Instruments set 4 (IS4):

$$
\begin{aligned}
\mathbf{w}_{t} & =\left(\pi_{t-1}, x_{t-1}, \mathbb{E}_{t-1} \tilde{\pi}, \tilde{\sigma}_{t-1}^{\pi}, \Delta i_{t-1}\right)^{\prime} \\
\mathbf{z}_{t} & =\left(\pi_{t-1}, \pi_{t-2}^{2}, x_{t-1}, x_{t-1}^{2}, \mathbb{E}_{t-1} \tilde{\pi},\left(\mathbb{E}_{t-1} \tilde{\pi}\right)^{2}, \tilde{\sigma}_{t-1}^{\pi},\left(\tilde{\sigma}_{t-1}^{\pi}\right)^{2}, \Delta i_{t-1}, \Delta i_{t-1}^{2}\right)^{\prime} .
\end{aligned}
$$

By choosing different sets of instruments, we may not only check the robustness of our results, but also evaluate the effects of having nonlinear combinations of exogenous variables as potential instruments.

The results of the linear estimation are illustrated in Table 3. Some important facts emerge from the table. First, it is clear that, when nonlinear instruments are used (IS2 and IS4), the persistence of past inflation (inflation inertia) is higher and the effect of inflation expectations is lower, as well as the effect of the past output gap. Second, the inclusion of real exchange rates as instruments does not alter the estimation results. Finally, the test described in Section 4 strongly rejects the null hypothesis of linearity, regardless of which instruments are used.

As linearity is strongly rejected, we proceed by estimating a smooth transition version of the Phillips Curve. Our specification has the following form:

$$
\begin{aligned}
\pi_{t}= & \bar{\pi}+\beta_{1}^{L} \pi_{t-1}+\beta_{3}^{L} x_{t-1}+\beta_{4}^{L} \mathbb{E}_{t} \tilde{\pi} \\
& +\left[\tilde{\pi}+\beta_{1}^{N} \pi_{t-1}+\beta_{3}^{N} x_{t-1}+\beta_{4}^{N} \mathbb{E}_{t} \tilde{\pi}\right] f\left(\tilde{\sigma}_{t}^{\pi} ; \gamma, c\right)+u_{t} .
\end{aligned}
$$

We present the estimates in Table 4. We report only the results concerning the instrument sets 3 (IS3) and 4 (IS4). The results with instrument sets 1 (IS2) and 2 (IS2) are not substantially different, and hence are omitted. For each instrument set, Table 4 reports two different estimates: one with the two step procedure to compute the "optimal" instruments, as in Section ??; and another set with only $\mathbf{z}_{t}$ as the instruments ("raw" instruments), that is, without the optimality correction. 
TABle 3. Linear Phillips Curve: Parameter Estimates.

\begin{tabular}{|c|c|c|c|c|}
\hline \multicolumn{5}{|c|}{$\begin{array}{l}\text { The table shows parameter estimates for equation } \pi_{t}=\bar{\pi}+\beta_{1} \pi_{t-1}+ \\
\beta_{2} x_{t-1}+\beta_{3} \mathbb{E}_{t} \tilde{\pi}+u_{t} \text {, where } \pi_{t} \text { is the annualized monthly inflation rate } \\
\pi_{t}, x_{t} \text { is the output gap and } \mathbb{E}_{t} \tilde{\pi} \text { is the inflation expectation defined as } \\
\text { in (14). The parameters are estimated with four different sets of instru- } \\
\text { ments (IS1-IS4). The table also reports the } p-\text { value of the linearity test. } \\
\text { The transition variable is } \tilde{\sigma}_{t}^{\pi} \text {. }\end{array}$} \\
\hline Coefficient & IS1 & IS2 & IS3 & IS4 \\
\hline $\bar{\pi}$ & $\begin{array}{l}0.0310 \\
(0.0065)\end{array}$ & $\begin{array}{l}0.0302 \\
(0.0065)\end{array}$ & $\begin{array}{l}0.0313 \\
(0.0066)\end{array}$ & $\begin{array}{l}0.0301 \\
(0.0065)\end{array}$ \\
\hline$\pi_{t-1}$ & $\begin{array}{l}0.1576 \\
(0.1072)\end{array}$ & $\begin{array}{l}0.2130 \\
(0.1041)\end{array}$ & $\begin{array}{l}0.1322 \\
(0.1110)\end{array}$ & $\begin{array}{l}0.2151 \\
(0.1042)\end{array}$ \\
\hline$x_{t-1}$ & $\begin{array}{l}0.5153 \\
(0.1759)\end{array}$ & $\begin{array}{l}0.4738 \\
(0.1738)\end{array}$ & $\begin{array}{l}0.5344 \\
(0.1779)\end{array}$ & $\begin{array}{l}0.4722 \\
(0.1738)\end{array}$ \\
\hline $\mathbb{E}_{t} \tilde{\pi}$ & $\begin{array}{l}3.1373 \\
(0.5031) \\
\end{array}$ & $\begin{array}{l}2.7942 \\
(0.4803) \\
\end{array}$ & $\begin{array}{l}3.2947 \\
(0.5315) \\
\end{array}$ & $\begin{array}{l}2.7811 \\
(0.4807) \\
\end{array}$ \\
\hline \multicolumn{5}{|c|}{$\underline{\text { Linearity Test }}$} \\
\hline & IS1 & IS2 & IS3 & IS4 \\
\hline$p$-values & 0.0006 & 0.0038 & 0.0008 & 0.0090 \\
\hline
\end{tabular}

The results can be summarized as follows. First, the estimated location of the transition $(\widehat{c})$ is almost the same in all the cases considered, and the transition is relatively smooth, although there are not many observations along the transition path. The analysis of the logistic function in Figure 6 confirms that the regime switches occur in periods when expectations uncertainty is higher. Indeed, the period can be separated into three sub-samples: (i) Before 2001, the implementation phase; (ii) 2001 - 2002, the stress test; and (iii) After 2002, the restoration of credibility. Hence, we can characterize the two extreme regimes as low uncertainty (regime 1) and high uncertainty (regime 2). Second, the persistence (inflation inertia) is high in the first regime, but almost vanishes in the high uncertainty regime, although it is worth noting the low significance of the coefficien 12 . In addition, the output gap is significant only when inflation uncertainty is high . Finally, inflation expectations are more important, as expected, in regime 2 (high uncertainty).

8.4. Implementing IT: Before 2000. Despite the adoption of IT in Brazil having occurred during a foreign exchange crisis, the transition to the new regime in 1999 was relatively smooth. Against the pessimistic views, inflation at the end of 1999 reached the one-digit level mark (8.9 percent), while annual GDP grew by almost 1 percent ( 0.8 percent). The response of the Brazilian government and the $\mathrm{BCB}$ to the crisis combined fiscal consolidation, a strong commitment with price stability, and external financial support. The analysis of the logistic function in Figure 6 confirms the economy was in a low uncertainty period (regime 1).

After the initial transition phase, with the normalization of financial conditions and under the effects of significant interest rate cuts, inflation ended 2000 at the 6 percent mid-point target, with robust economic growth of 4.4 percent. During this period, our first-regime estimates shows the irrelevance of output gap for inflation dynamics, which was driven by lagged inflation $(0.3-0.4)$ and inflation expectations $(0.6$ -

\footnotetext{
${ }^{12}$ This may be due to the restricted number of observations.
} 
TABle 4. Nonlinear Phillips Curve: Parameter Estimates.

\begin{tabular}{|c|c|c|c|c|}
\hline \multicolumn{5}{|c|}{$\begin{array}{l}\text { The table } \\
\beta_{4}^{L} \mathbb{E}_{t} \tilde{\pi}+ \\
\text { struments } \\
\text { parenthese }\end{array}$} \\
\hline (2) & \multicolumn{4}{|c|}{$\underline{\text { Instrument Set } 3}$} \\
\hline \multirow[b]{3}{*}{$\bar{\pi}$} & \multicolumn{2}{|c|}{ "Raw" Instruments } & \multicolumn{2}{|c|}{ “Optimal” Instruments } \\
\hline & First Regime & Second Regime & First Regime & Second Regime \\
\hline & $\begin{array}{l}0.0267 \\
(0.0092)\end{array}$ & $\begin{array}{l}0.0192 \\
(0.0164)\end{array}$ & $\begin{array}{l}0.0257 \\
(0.0096)\end{array}$ & $\begin{array}{l}0.0222 \\
(0.0185)\end{array}$ \\
\hline$\pi_{t-1}$ & $\begin{array}{l}0.3118 \\
(0.1542)\end{array}$ & $\begin{array}{r}-0.3075 \\
(0.2070)\end{array}$ & $\begin{array}{l}0.3999 \\
(0.1558)\end{array}$ & $\begin{array}{r}-0.2312 \\
(0.2107)\end{array}$ \\
\hline$x_{t-1}$ & $\begin{array}{l}0.0417 \\
(0.2894)\end{array}$ & $\begin{array}{l}0.8853 \\
(0.3823)\end{array}$ & $\begin{array}{l}0.0108 \\
(0.2921)\end{array}$ & $\begin{array}{l}0.8221 \\
(0.3932)\end{array}$ \\
\hline $\mathbb{E}_{t} \widetilde{\pi}$ & $\begin{array}{l}1.8351 \\
(1.0809)\end{array}$ & $\begin{array}{l}1.8613 \\
(1.1632)\end{array}$ & $\begin{array}{l}0.6341 \\
(1.0960)\end{array}$ & $\begin{array}{l}2.0609 \\
(1.2495)\end{array}$ \\
\hline$\gamma$ & \multicolumn{2}{|c|}{$\underset{(-)}{19.2964}$} & \multicolumn{2}{|c|}{$\underset{(-)}{19.3367}$} \\
\hline \multirow[t]{4}{*}{$c$} & \multicolumn{2}{|c|}{$\begin{array}{l}1.0661 \\
(0.1130)\end{array}$} & \multicolumn{2}{|c|}{$\begin{array}{l}1.0479 \\
(0.1030)\end{array}$} \\
\hline & \multicolumn{4}{|c|}{ Instrument Set 4} \\
\hline & \multicolumn{2}{|c|}{ "Raw" Instruments } & \multicolumn{2}{|c|}{ “Optimal” Instruments } \\
\hline & First Regime & Second Regime & First Regime & Second Regime \\
\hline $\bar{\pi}$ & $\begin{array}{l}0.0296 \\
(0.0094)\end{array}$ & $\begin{array}{l}0.0163 \\
(0.0184)\end{array}$ & $\begin{array}{l}0.0264 \\
(0.0095)\end{array}$ & $\begin{array}{l}0.0220 \\
(0.0194)\end{array}$ \\
\hline$\pi_{t-1}$ & $\begin{array}{l}0.3313 \\
(0.1522)\end{array}$ & $\begin{array}{r}-0.2252 \\
(0.2049)\end{array}$ & $\begin{array}{l}0.3832 \\
(0.1536)\end{array}$ & $\begin{array}{r}-0.2046 \\
(0.2102)\end{array}$ \\
\hline$x_{t-1}$ & $\begin{array}{l}0.0044 \\
(0.2879)\end{array}$ & $\begin{array}{l}0.8956 \\
(0.3892)\end{array}$ & $\begin{array}{l}0.0043 \\
(0.2930)\end{array}$ & $\begin{array}{l}0.8477 \\
(0.3964)\end{array}$ \\
\hline $\mathbb{E}_{t} \widetilde{\pi}$ & $\begin{array}{l}0.8445 \\
(1.0201)\end{array}$ & $\begin{array}{l}2.3388 \\
(1.2209)\end{array}$ & $\begin{array}{l}0.9162 \\
(1.0472)\end{array}$ & $\begin{array}{l}1.7211 \\
(1.2165)\end{array}$ \\
\hline$\gamma$ & & 6842 & & $\begin{array}{l}7301 \\
-)\end{array}$ \\
\hline$c$ & & $\begin{array}{l}8291 \\
1035)\end{array}$ & & $\begin{array}{l}668 \\
1084)\end{array}$ \\
\hline
\end{tabular}

1.8). However, during 2000 a series of important shocks occurred, notably: oil prices had double since 1999, while the prices of technology firms fells sharply, with the meltdown of NASDAQ. At the same time, monetary policy conditions were tightened in the USA, with the Federal Funds Rate being raised to 6.5 percent in May 2000, from 5.5 percent at the end of 1999.

By the end of 2000, while the performance of the economy was positive, the accelerated rate of growth of the Brazilian economy, combined with the US and Global slowdown, pointed to difficulties ahead. The Brazilian economic recovery that began at the end of 1999 was based on strong credit expansion, increasing exports of industrial goods, and agricultural price recovery. This recovery, however, combined with increasing oil prices and the US slowdown, adversely affected the balance of trade, which entered negative territory (12 months) in September 2000 after a period of recovery following the depreciation of the Real in early 1999. The Brazilian core IPCA inflation started to show a growth trend after November 2000. 

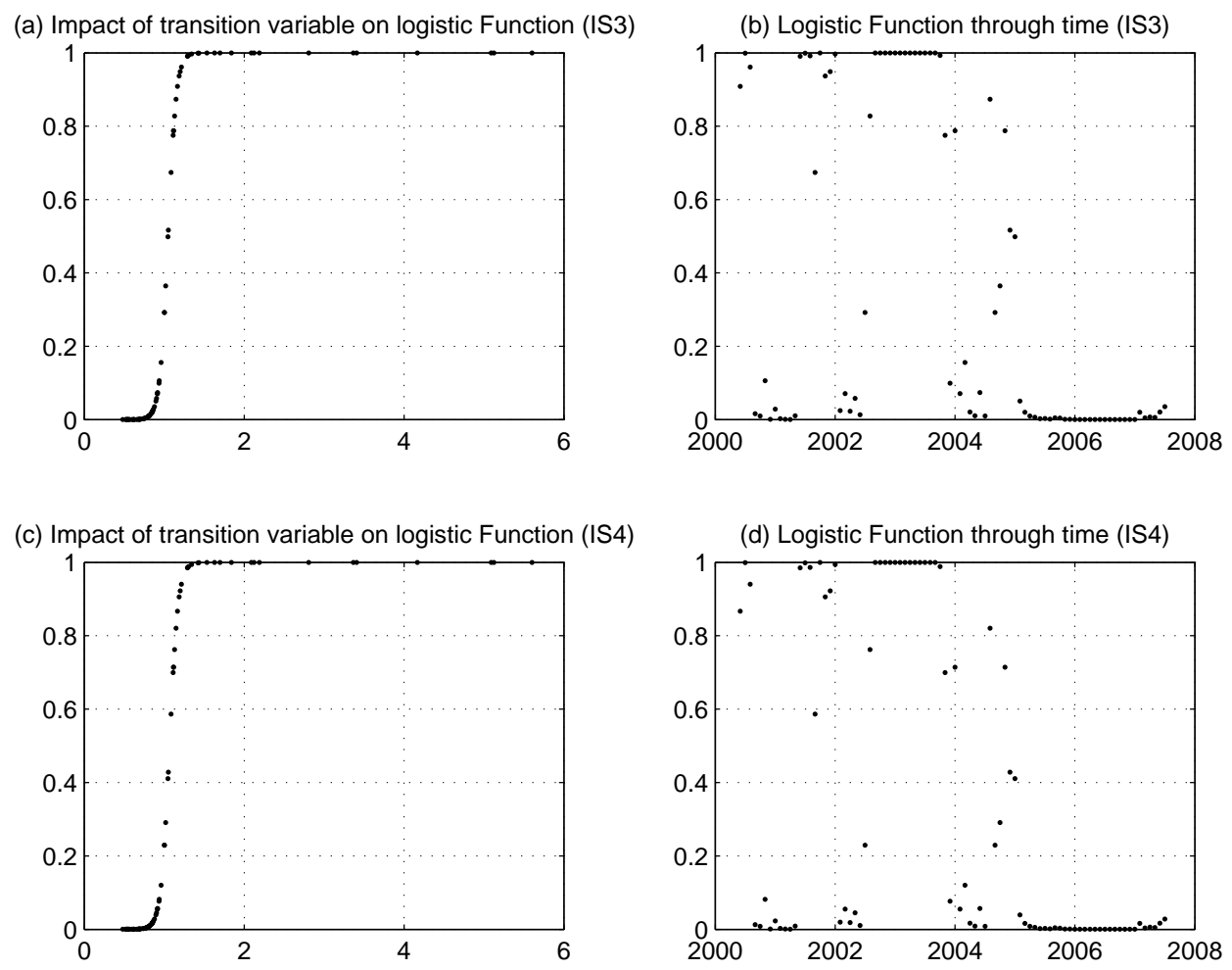

FIgURE 6. Estimated logistic function. Panel (a): transition function versus transition variable (IS3). Panel (b): transition function across time (IS3). Panel (c): transition function versus transition variable (IS4). Panel (d): transition function across time (IS4).

8.5. Inflation targeting under stress: 2001 - 2002. The year 2001 was marked by a series of adverse shocks, most notably: the Argentina default, officially announced in the fourth quarter of 2001, the energy crises in Brazil, and the September 11, 2001 attack. In the beginning of the year, consumer price inflation was above expectations, while the core inflation trend was incompatible with the 4 percent inflation target for the year. After reducing the Selic rate to 15.25 percent in January, the BCB started in March the first monetary policy tightening cycle of the inflation targeting regime. After an initial 50 basis points increase, the tightening cycle was interrupted only in July, with the Selic rate reaching 19 percent. The policy rate remained unchanged from August 2001 to February 2002, when the Central Bank began the easing process, although for a brief period of time. The series of adverse events produced during 2001 significant exchange rate depreciation, hovering around 20 percent. At the end of 2001, inflation reached 7.7 percent (3.7 percentage points above the 4 percent target) and the economy grew 1.3 percent. The logistic function in Figure 6 shows that the economy was in a high uncertainty period (regime 2). In this scenario, lagged inflation is no longer a good proxy for future inflation, which explains why persistence is low in the period. The increased relevance of inflation expectations $(1.7$ - 2.3) and output gap (0.82 0.89 ) in inflation dynamics, highlights the importance of anchoring expectations. 
Even though the target was not reached, the results obtained in the face of an extremely adverse scenario were satisfactory, revealing the inflation targeting regime as an effective and flexible framework to pin down expectations. Inflation expectations for 2002, gauged at the end of 2001, were still below 5 percent. The way monetary policy was conducted with the swift reaction after the September 11, 2001 terrorist attacks kept expectations under control and made economic agents believe that the 2001 adverse inflationary shock would be dissipated during the following year.

The year 2002 began with the view that the end of the energy crisis, combined with an improved international environment, would allow some flexibility in the conduct of monetary policy. In fact, a considerable exchange rate appreciation occurred (from a $2.80 \mathrm{R} \$ / \mathrm{US} \$$ just after September 11 to 2.40 $\mathrm{R} \$ / \mathrm{US} \$$ in the beginning of May 2002). In this context, the monetary policy was relaxed in the beginning of the year, with the Selic rate being reduced from 19 percent in February to 18 percent in June. However, later in the year, the uncertainty associated with the presidential election sets off an unprecedented confidence crisis, leading to a sharp exchange rate depreciation and to very unfavorable debt-dynamics. During that time, despite a number of arguments arose, suggesting that particular circumstances distorted the transmission mechanism from monetary policy, which was then bound for defeat against inflation, Brazil did succeed in securing disinflation through monetary tightening, with a perceptible contribution from the aggregate demand transmission channel.

The commitment assumed by the new President to sustain sound macroeconomic policies, combining fiscal discipline, a floating exchange rate regime, and the inflation targeting framework, was crucial to dissipate the fear associated with changes in the course of the economy and related to debt sustainability. From September to December 2002, the Central Bank increased its policy rate from 18 percent to 25 percent. However, the sharp exchange rate depreciation during the year yielded a considerable increase in inflation, which ended 2002 at 12.5 percent, and modest GDP growth of 1.9 percent. Although the inflation targeting regime was unable to anchor expectations during that year, the months that followed this episode proved that inflation targeting has been a useful framework to align market expectations with government objectives.

8.6. Reconstructing credibility: After 2002. In January 2003, the Central Bank sent an open letter to the Minister of Finance explaining why the inflation targets were breached, and made explicit estimates of the size of the shocks and their persistence. The Central Bank added to the original inflation target for 2002 (4 percent), part of the breach experienced in the previous year, to account for inertia effects (inflation carryover from the 2002 shock), and for the impact on administered prices that, by contract provisions, are adjusted according to past inflation. These two effects let the Central Bank adjust the inflation target for 2003 to 8.5 percent. The Central Bank made explicit reference to the fact that, after the sharp increase in inflation in 2002, attempting to achieve the original inflation target of 4 percent for 2003 would require a sizeable output sacrifice. Inflation in 2003 fell by more than 3 percentage points, ending at 9.3 percent, which was close to the adjusted target, and GDP declined by a modest 0.2 percent. The Central Bank was not able to achive this on its own. The new government not only supported the inflation targeting regime, but also pursued tight spending policies that resulted in a primary budget 
surplus in 2003 of 4.3 percent of GDP. Just in line with these facts, the analysis of the logistic function in Figure 6 confirms that the economy returned to regime 1 (low uncertainty period), with inflation primarily driven by lagged inflation and inflation expectations.

The strong recovery in 2004, with growth reaching almost 5 percent and with employment increasing at a two-digit rate, required a gradual but firm response of the Central Bank to fight emerging inflationary pressures and to prevent these pressures from contaminating inflationary expectations. From September 2004 to May 2005, the Central Bank raised its policy rate by 3.75 percentage points to 19.75 percent. Moreover, the government announced in September 2004 a change in the primary surplus target for 2004, from 4.25 to 4.5 percent of GDP. Inflation, despite some acceleration during the second half of 2004, ended the year at 7.6 percent, which was above the 5.5 percent target, but within the tolerance interval.

In September 2004, when it became clear to the Central Bank that the 5.5 percent target for 2004 would not be fulfilled, and it was possible to project with greater accuracy the 2004 deviation, the Central Bank announced 5.1 percent as its operational target to be pursued in 2005.

\section{Conclusions}

In this paper we considered the estimation of smooth transition regression models with endogenous variables. Different nonlinear instrumental variable (IV) estimation methods have been discussed, and the asymptotic properties of the estimators were analyzed when the data are formed by weakly dependent stochastic processes. A linearity test based on the Taylor expansion of the logistic function was extended to the case of endogenous regressors, and its small sample properties were checked through simulations. The small sample properties of the nonlinear IV estimators were also analyzed by simulation. Finally, a nonlinear Phillips Curve, for emerging economies was estimated with Brazilian data under an Inflation Targeting regime. The empirical results showed strong support for a nonlinear specification of the Phillips curve where the transitions were related to inflation uncertainty with respect to the target.

\section{ACKNOWLEDGEMENTS}

The second author wishes to acknowledge the financial support of the Australian Research Council, and the third author acknowledges the CNPq for partial financial support. The authors wish to thank participants at the "Recent Developments in Econometric Theory" conference, Kyoto, Japan, July 2006, and the "International Symposium on Recent Developments of Time Series Econometrics", Xiamen, China, May 2008, for helpful comments and suggestions.

\section{Appendix A. Proofs}

A.1. Proof of Theorem 1 Assumptions 2 and 3 guarantee that the model is identified. Under Assumptions 6 and 45, the proof follows from the same steps as in the proof of Theorem 8.1.1 in Amemiya (1985, p. 246). 
A.2. Proof of Theorem 2, The proof of the first part of the above theorem follows along the same lines as the proof of Theorem 8.1.2 of Amemiya (1985, p. 247). The second part of the theorem follows from the same steps in Amemiya (1975, p.381).

\section{REFERENCES}

Alves, S., AND W. Areosa (2005): “Targets and Inflation Dynamics,” Texto para Discussão 100, Banco Central do Brasil. AmemiYA, T. (1974): “The Nonlinear Two-Stage Least-Squares Estimator,” Journal of Econometrics, 2, 105-110.

(1975): “The Nonlinear Limited-Information Maximum-Likelihood Estimator and the Modified Nonlinear Two-Stage Least-Squares Estimator,” Journal of Econometrics, 3, 375-386.

(1977): "The Maximum Likelihood and the Nonlinear Three-Stage Least Squares Estimator in the General Nonlinear Simultaneous Equation Model," Econometrica, 45, 955-968. (1985): Advanced Econometrics. Harvard University Press, Cambridge.

Bacon, D. W., And D. G. Watts (1971): "Estimating the Transition Between Two Intersecting Lines," Biometrika, 58, 525-534.

BALL, L., AND N. SHERIDAN (2003): “Does Iflation Targeting Matter?,” Working Paper 9577, NBER.

Bowden, R., AND D. TuRKIngton (1981): "A Comparative Study of Instrumental Variables Estimators for Nonlinear Simultaneous Models," Journal of the American Statistical Association, 76, 988-995.

CAlvo, G. (1993): "Staggered Prices in a Utility Maximizing Framework," Journal of Monetary Economics, 12, $383-398$.

CANER, M., AND B. HANSEN (2004): "Instrumental Variable Estimation of a Threshold Model," Econometric Theory, 20, 813-843.

CARneIro, D. (2000): “Inflation Targeting in Brazil: What Difference Does a Year Make?," Textos para Discussão 429, Pontifícia Universidade Católica do Rio de Janeiro.

Cerisola, M., AND R. Gelos (2005): “What Drives Inflation Expectations in Brazil? An Empirical Analysis,” Working Paper WP/05/109, IMF.

Chan, K. S., AND H. Tong (1986): “On Estimating Thresholds in Autoregressive Models,” Journal of Time Series Analysis, 7, 179-190.

Choi, I., AND P. SAikKonen (2004a): “Cointegrating Smooth Transition Regressions,” Econometric Theory, 20, 301-340.

- (2004b): “Testing Linearity in Cointegrating Smooth Transition Regressions,” Econometrics Journal, 7, 341-365.

CUKIERMAn, A., AND P. WACHTEL (1979): "Differential Inflationary Expectations and the Variability of the Rate of Inflation: Theory and Evidence," American Economic Review, 69, 595-609.

DAVIDSON, R., AND J. G. MACKInNON (1993): Estimation and Inference in Econometrics. Oxford University Press, New York, NY.

Eliasson, A.-C. (1999): "Is the Short-Run Phillips Curve Nonlinear? Empirical Evidence for Australia, Sweden and the United States," Working Paper Series in Economics and Finance 330, Stockholm School of Economics.

Galí, J., AND M. Gertler (1999): “Inflation Dynamics: A Structural Econometric Investigation,” Journal of Monetary Economics, 44, 195-222.

GoldFeld, S. M., AND R. QUANDT (1972): Nonlinear Methods in Econometrics. North Holland, Amsterdam.

Granger, C. W. J., AND T. Teräsvirta (1993): Modelling Nonlinear Economic Relationships. Oxford University Press, Oxford.

HAnsen, L. (1982): “Large Sample Properties of Generalized Method of Moments Estimators,” Econometrica, 40, 10291054.

Kelejian, H. (1971): "Two-Stage Least Squares and Econometric Systems Linear in Parameters but Nonlinear in the Endogenous Variables," Journal of the American Statistical Association, 66, 373-374. 
Laxton, D., G. Meredith, AND D. Rose (1995): “Asymmetric effects of economic activity on inflation,” IMF Staff Papers, 42, 344-374.

LI, W. K., S. Ling, AND M. MCAlEeR (2002): "Recent Theoretical Results for Time Series Models with GARCH Errors," Journal of Economic Surveys, 16, 245-269.

Logue, D., AND T. Willett (1976): "A Note on the Relation between the Rate and Variability of Inflation," Economica, 43, 151-158.

Lundbergh, S., AND T. TERÄSvirTa (1998): "Modelling Economic High-Frequency Time Series with STAR-STGARCH Models," Working Paper Series in Economics and Finance 291, Stockholm School of Economics.

LuukKonen, R., P. SAikKonen, And T. Terësvirta (1988): “Testing Linearity Against Smooth Transition Autoregressive Models," Biometrika, 75, 491-499.

MCAlEer, M. (2005): “Automated Inference and Learning in Modeling Financial Volatility,” Econometric Theory, 21, 232261.

Medeiros, M., AND A. Veiga (2005): “A Flexible Coefficient Smooth Transition Time Series Model,” IEEE Transactions on Neural Networks, 16, 97-113.

MirA, S., AND A. Escribano (2000): "Nonlinear Time Series Models: Consistency and Asymptotic Normality of NLS Under New Conditions," in Nonlinear Econometric Modeling in Time Series Analysis, ed. by W. A. Barnett, D. Hendry, S. Hylleberg, T. Teräsvirta, D. Tjøsthein, and A. Würtz, pp. 119-164. Cambridge University Press.

Mishkin, F. (2004): “Can Inflation Targeting Work in Emerging Market Countries?," in Conference in Honor of Guilhermo Calvo.

Mishinin, F., AND K. Schmidt-Hebbel (2001): “One Decade of Inflation Targeting in the World: What Do We Know and What Do We Need to Know?,” Working Paper 8397, NBER.

Musso, A., L. StracCA, AND D. VAn DiJK (2007): “Instability and Nonlinearity in the Euro Area Phillips Curve," Working Paper Series 811, European Central Bank.

NEWEY, W. (1990): "Efficient Instrumental Variable Estimation of Nonlinear Models," Econometrica, 58, 809-837.

NeWEy, W., AND J. Powell (2003): “Instrumental Variable Estimation of Nonparametric Models,” Econometrica, 71, 1565-1578

Nobay, A., And D. Peel (2000): “Optimal Monetary Policy with a Nonlinear Phillips Curve,” Economics Letters, 67, 159-164.

Schaling, E. (1999): “The Non-Linear Phillips Curve and Inflation Forecast Targeting - Symmetric Versus Asymmetric Monetary Policy Rules,” Working Paper Series 98, Bank of England.

Stock, J., J. Wright, AND M. Yogo (2002): “A Survey of Weak Instruments and Weak Identification in Generalized Method of Moments," Journal of Business and Economic Statistics, 20, 518-529.

Suarez-Fariñas, M., C. E. Pedreira, And M. C. Medeiros (2004): "Local Global Neural Networks: A New Approach for Nonlinear Time Series Modeling,” Journal of the American Statistical Association, 99, 1092-1107.

TERÄSVIRTA, T. (1994): "Specification, Estimation, and Evaluation of Smooth Transition Autoregressive Models," Journal of the American Statistical Association, 89, 208-218.

- (1998): "Modelling Economic Relationships with Smooth Transition Regressions," in Handbook of Applied Economic Statistics, ed. by A. Ullah, and D. E. A. Giles, pp. 507-552. Dekker.

van Dijk, D., T. Teräsvirta, AND P. H. Franses (2002): "Smooth Transition Autoregressive Models - A Survey of Recent Developments," Econometric Reviews, 21, 1-47.

Woodford, M. (2004): "Inflation Targeting and Optimal Monetary Policy," Federal Reserve Bank of St. Louis Review, 86, 14-41. 